\title{
Los grandes proyectos hidráulicos y las políticas antipalúdicas: Un estudio comparativo entre el Plan de Riegos del alto Aragón y el Canal de Panamá
}

\author{
The Great Hydraulic Projects and Anti-Malarial Policies: \\ A Comparative Study between the Irrigation Plan \\ of the Alto Aragon and the Panama Canal
}

\author{
Jesús R. Navarro-García \\ ORCID iD: http://orcid.org/0000-0003-3772-9826 \\ Escuela de Estudios Hispano-Americanos, CSIC
}

Jorge L. Chinea

ORCID iD: http://orcid.org/0000-0002-6656-8710

Wayne State University

El Canal de Panamá y los sistemas de riego que se implementaron en la Cuenca Hidrográfica del Ebro desde finales del siglo XIX son muestras representativas de las implicaciones sanitarias que estas obras suponían en unos territorios que experimentaban profundas transformaciones ambientales y que recibian una abundante mano de obra que, además, se veía obligada a residir en las proximidades de zonas convertidas en hábitats muy favorables para el desarrollo de los vectores de la malaria. Pese a incorporar al estudio dos zonas muy diferentes entre sí, se observa cómo la zona con menores precipitaciones también fue capaz de generar fases epidémicas de la enfermedad, no solo en la fase de construcción de los embalses y canalizaciones sino también con la puesta en marcha de los regadíos.

PAlabras Clave: Malaria; Canal de Panamá; Cuenca Hidrográfica del Ebro; Obras Hidráulicas.

The Panama Canal and the irrigation systems that were implemented in the Ebro Hydrographic Basin since the end of the 19th century are representative samples of the health implications that these projects entailed in territories that underwent profound environmental transformations and that received an abundant workforce that, in addition, was forced to reside in the vicinity of areas converted into habitats very favorable for the development of malaria vectors. Although this study incorporates two very different zones, the area with the lowest rainfall (the Ebro Basin) was also able to generate epidemic phases of the disease, not only in the construction phase of the reservoirs and the accompanying canalization, but also when irrigation was launched.

Keywords: Malaria; Panama Canal; Ebro Hydrographic Basin; Hydraulic works.

Copyright: (C) 2019 CSIC. Este es un artículo de acceso abierto distribuido bajo los términos de la licencia de uso y distribución Creative Commons Reconocimiento 4.0 Internacional (CC BY 4.0). 
«Me encontraba con otros niños con caritas arrugadas, como de viejos, y esqueléticos por el hambre, con el pelo lleno de piojos y costras, pero la mayoría tenían grandes panzas hinchadas, enormes, y la cara amarilla y agotada por el paludismo»

Carlo Levi, Cristo se detuvo en Éboli, 1945

\section{Malaria y obra pública ${ }^{1}$}

Las cifras que acompañan a la malaria hoy en día siguen estando al nivel de la considerada — con toda justicia — como la enfermedad más mortífera en la historia de la humanidad. Pese a que se lleva ya más de todo un siglo luchando contra ella desde muchos frentes hoy sigue siendo la tercera enfermedad por infección con más muertes a sus espaldas. Si bien se erradicó de latitudes templadas como Estados Unidos y Europa en los años sesenta del siglo pasado, aún está presente en casi cien países, con más de doscientos millones de casos a nivel mundial en 2015 y más de cuatrocientas mil muertes el mismo año, según las fuentes más conservadoras, ubicándose la mayor parte de los casos en el África Subsahariana, en donde la enfermedad ocasiona también grandes gastos tanto a los particulares como a los Estados. ${ }^{2}$

1 Este trabajo de investigación se fraguó dentro de las actividades científicas del proyecto de excelencia HUM-03215, cofinanciado por la Junta de Andalucía y los Fondos FEDER, entre el año 2008 y 2012. Asimismo, se disfrutó de una ayuda económica de la Junta de Andalucía para realizar una estancia de investigación en la Universidad de Zaragoza (Facultad de Ciencias Económicas y Empresariales, Departamento de Análisis Económico), que permitió a uno de los autores trabajar durante el año 2009 en el Archivo de la Confederación Hidrográfica del Ebro y el Archivo Histórico Provincial de Lleida. También reconocemos el apoyo de Wayne State University para investigar en el Rockefeller Center Archives, Westchester, Nueva York, durante el mes de junio de 2015. En estos archivos debemos agradecer especialmente su colaboración al responsable del Archivo de la Confederación Hidrográfica del Ebro (CHE), José Manuel Almécija, y a todo el personal del Archivo Histórico Provincial de Lleida, quienes hicieron fácil todos los trámites de consulta. Un avance parcial de este trabajo se presentó en el II Congreso Latinoamericano de Historia Económica, celebrado en la Universidad Nacional Autónoma de México en 2010. A partir de estas referencias documentales se ha seguido trabajando desde entonces en temas conectados a las políticas hidráulicas y sanitarias en el ámbito, sobre todo, español. Agradecemos también a los evaluadores anónimos de la revista sus comentarios constructivos para poder ofrecer una versión más rica de nuestro trabajo.

2 Una excelente visión y puesta al día de algunas cuestiones básicas en el estado de la malaria a nivel mundial a inicios de la segunda década del siglo XXI puede seguirse en el especial de $L a$ Vanguardia, Barcelona, 25 de abril de 2010, 34-37, con firmas como las de Casamitjana, Menéndez, Bassat y Alonso (todos ellos del Centro de Investigación en Salud Internacional de Barcelona, CRESIB), Newman (Organización Mundial de la Salud, OMS) y Rabinovich (Fundación Bill \& Melinda Gates). También puede verse Protocolos de la Red Nacional de Vigilancia Epidemiológica. Protocolo de Vigilancia de Paludismo. Instituto de Salud Carlos III. Madrid, 2015, y la web de la OMS para datos más recientes (www.who.int/features/factfiles/malaria/es, consultada en noviembre de 2017). Véase en Mesa Venegas, 2017 una valoración muy actual de las perspectivas de lucha contra la enfermedad, a la que considera la autora «uno de los principales desafíos de salud pública a nivel mundial». 
Con todo, los progresos han sido evidentes. Baste recordar que, a finales del siglo XIX, solo en la India la malaria podía causar la muerte de un millón de personas al año o que en España la tasa de mortalidad por malaria en 1900 era de 25,3 por cada 100.000 habitantes. ${ }^{4}$ En 1918 había en España 1.818 términos municipales palúdicos (abarcando 313.200 hectáreas), con una morbilidad superior a los trescientos mil casos y más de dos mil fallecimientos al año. ${ }^{5}$ Pero a pesar de los avances experimentados y de los grandes esfuerzos desplegados en más de un siglo y en muchos frentes no se han encontrado ni vacunas ni medicamentos ${ }^{6}$ que prevengan de la enfermedad, a pesar del importante papel que han desempeñado los gobiernos de las naciones, las instituciones internacionales sanitarias, las instituciones privadas, la sociedad civil, etc., en el control de los vectores, el desarrollo de insecticidas y fármacos, en los diagnósticos precoces, etc. ${ }^{7}$ Es conveniente recordar aquí aquellas palabras del intelectual español Luis Bello en las que aludía en 1927 a la malaria y a la ya entonces considerada «larga batalla» contra la enfermedad: «O será que estamos al principio de una gran campaña de una serie de grandes batallas, y lo hecho no pasa de tanteos, fintas, preparación y entrenamiento, en suma, para la verdadera guerra?». ${ }^{8}$ Esta larga lucha estuvo muy vinculada a las obras públicas y a los paralelos planes sanitarios que los estados acometieron en cuanto se conoció la etiología de la enfermedad, tras el descubrimiento del parásito por Laveran en 1880, y de que Ronald Ross lo localizara en 1898 en las glándulas salivales de los Anopheles. ${ }^{9}$ Una muestra temprana de la implicación de las instituciones públicas la tenemos en Italia, donde ya en 1900 se estableció el control estatal sobre la producción de quinina así como su distribución a precio muy reducido para tratamiento y profilaxis. Italia también reconoció en 1907 la malaria como enfermedad ocupacional por lo que los patronos tenían obligaciones de prevención y tratamiento a sus

3 McCullough, 2012, 363.

4 Rodríguez Ocaña et al., 2003a, 42.

5 Ibérica, 17 de octubre de 1925, 2, XXIV, 598, 229.

6 Hoy en día se trabaja en el uso de la bacteria Wolbachia para que no crezcan virus humanos en los mosquitos y en el uso de vacunas que provoquen respuestas inmunitarias ante la saliva del mosquito (Rodriguero, 2013; Xi, Khoo y Dobson, 2005; Sanicas, 2017), aunque los resultados todavía no sean definitivos.

7 Mesa Venegas, 2017, 167-168 y 173.

8 Bello, 1927, 254. Sobre su obra puede verse Ballesteros García, 2006. Es de destacar esta reflexión visionaria de Bello, sobre todo si la comparamos con las más triunfalistas de paludólogos como Russell (Rodríguez Ocaña et al., 2003a, 42-43).

9 McCullough, 2012, 362-363. Solo unas pocas especies (unas treinta de cuatrocientas) de Anopheles son vectores de importancia para transmitir la enfermedad (Sutter, 2000, 75). 
trabajadores. Más adelante, en 1923, todas las actividades antimaláricas se coordinaron a través de una Dirección General de Salud Pública asistida por un Comité Científico muy cualificado que se coordinaba con entidades locales y organizaciones como las compañías de ferrocarril, la Cruz Roja o el Ejército. ${ }^{10}$ En España habría que destacar el papel desempeñado por la Dirección General de Sanidad, publicando el estudio de los doctores Huertas y Mendoza en 1902 sobre el paludismo en Cáceres, o alentando la experiencia de 1903 del doctor Pittaluga suministrando a la población un compuesto de quinina, o la participación del Ministerio de Instrucción Pública en 1905 difundiendo carteles informativos sobre la prevención del paludismo. En el plan de obras de los Riegos del Alto Aragón, el Estado cubrió los costos relacionados con el suministro de quinina, así como con todas las obras relacionadas con la protección pasiva de las viviendas de los obreros y la eliminación de las láminas de agua en las obras. ${ }^{11}$

Ya desde principios del siglo

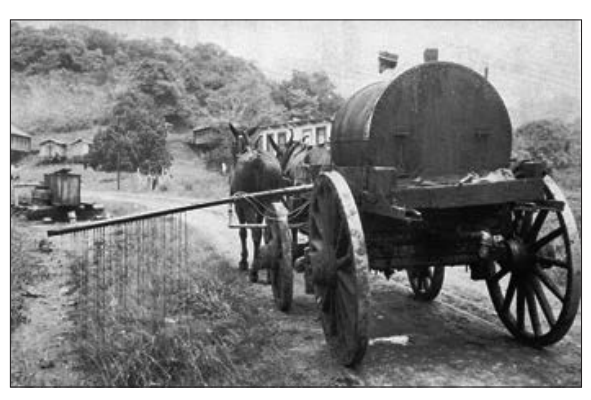

ImAGEN 1. Aplicación de insecticida sobre una zanja de las obras de construcción del Canal de Panamá. Fuente: Keller, 1983, 12. XX los proyectos hidráulicos alcanzaron un enorme desarrollo y a ellos no fueron ajenos ni España ni Panamá. Este desarrollo de la planificación hidráulica se vio acompañado, de forma paralela, por un avance espectacular en el conocimiento de la etiología del paludismo desde finales del siglo XIX y sobre todo desde los albores de la pasada centuria. Así, hubo un encuentro de las políticas estatales actuando en la planificación hidráulica y en la planificación sanitaria vinculada al paludismo. En España, la planificación hidráulica moderna podemos decir que arranca con la Ley de Aguas de 1879 y se consolida en 1902 con el I Plan Nacional de Obras Hidráulicas. Las obras que de ellos surgen y la consiguiente puesta en marcha de nuevos regadíos suponían un incremento potencial y real de los casos de paludismo en el país, una enfermedad que, por otro lado, experimentaba fuertes avances en su profilaxis.

10 Fantini, 2009, 73.

11 Rodríguez Ocaña y Perdiguero, 2009, 99-101. 


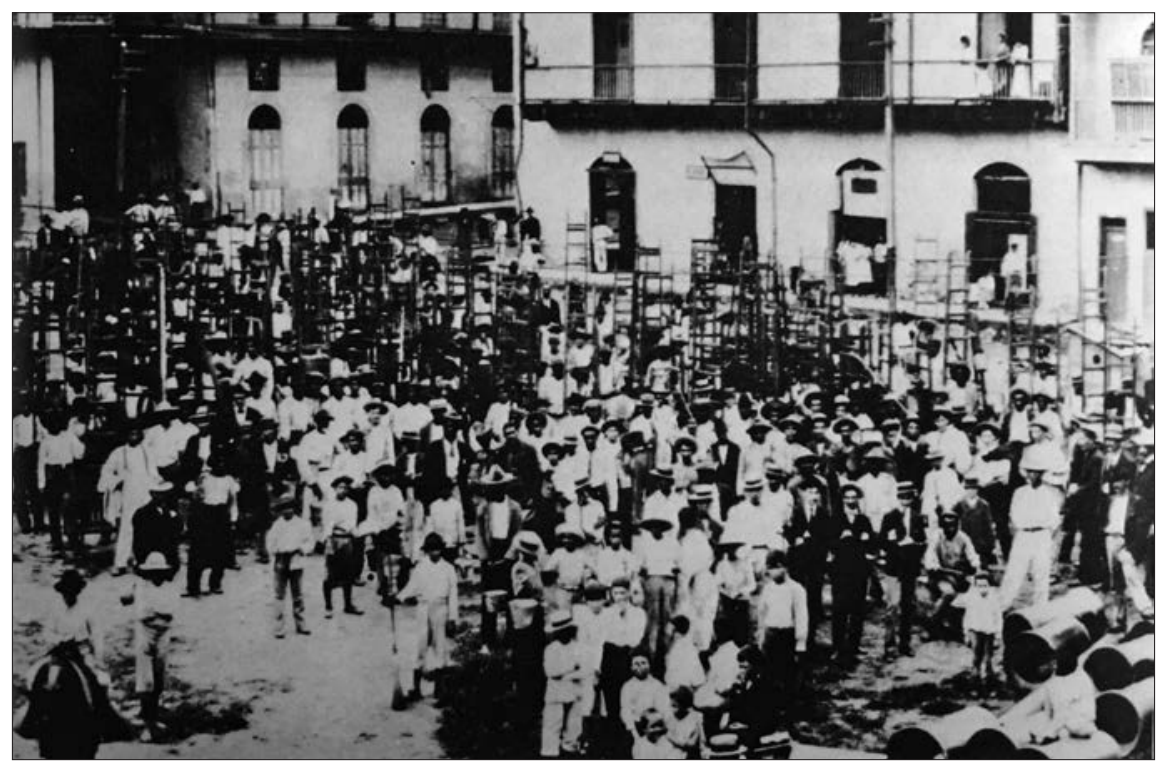

Imagen 2. Brigadas de fumigación en la Ciudad de Panamá durante la construcción del Canal. Fuente: McCullough, 2012.

En esta coyuntura de cambio de siglo se acometerán dos grandes proyectos de obras, uno de gran envergadura internacional y de repercusiones a nivel planetario como fue el Canal de Panamá (1881-1914), con el antecedente que supuso la construcción del Canal de Suez (1859-1869) y, en suelo panameño, la del trazado viario del Ferrocarril de Panamá (1850-1855), y otro también destacable en su envergadura a nivel español y europeo: el Plan de Riegos del Alto Aragón (1917), el mayor plan de regadíos europeo en su día. Ambos proyectos suponen por su magnitud un importante reto para los estados de cara a tratar de reducir lo más posible el número de fallecidos a consecuencia de las enfermedades transmitidas por los mosquitos en una obra hidráulica. Y precisamente en unos años en los que se están articulando las primeras estrategias de actuación basadas en los recientes descubrimientos médicos.

Ya en Panamá existía, como dijimos, el antecedente de la construcción del ferrocarril de Panamá, a mediados del siglo XIX, cuando nada se sabía de los modos de transmisión de la malaria y la fiebre amarilla por las picaduras de mosquito. Estas dos enfermedades, el cólera y alguna más 


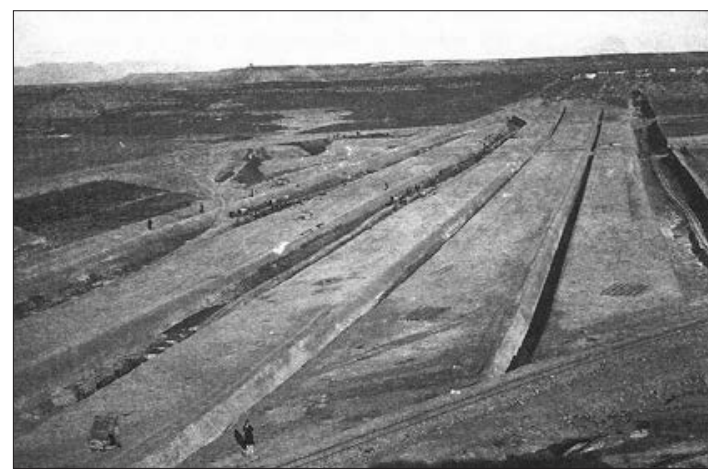

Imagen 3. Obras de la presa de Sotonera en 1922. Fuente: Un viaje de Ramón J. Sénder por los Riegos del Alto Aragón [1922], Comunidad de Riegos del Alto Aragón, 2001. como la disentería y la viruela pudieron ocasionar en la construcción de esta línea férrea de $75 \mathrm{~km}$ de longitud —uniendo las ciudades de Colón, en el Atlántico, y Panamá, en el Pacífico- más de doce mil muertes. ${ }^{12}$ El número de fallecidos debió ser todavía mayor en el caso del canal de Suez, iniciado pocos años después de que se acabara el ferrocarril panameño, y en la primera fase de construcción

del Canal de Panamá que abarca las dos últimas décadas del siglo XIX.13 En España el proceso es similar, pues la incidencia del paludismo en la obra pública (en el Canal de Urgel sobre todo) fue recordada durante mucho tiempo y se tuvo muy en cuenta cuando se inició el Plan de Riegos del Alto Aragón en 1917, cuando solo habían pasado apenas tres años de la apertura del Canal de Panamá. A nivel coyuntural, el inicio del Plan de Riegos del Alto Aragón coincide con un repunte de la mortalidad por paludismo en España entre 1914 y 1918, cuando se supera de nuevo la tasa de mortalidad de 10 por cada 100.000 habitantes. $^{14}$

Los antecedentes sobre incidencias palúdicas tienen que ver también con la construcción del ferrocarril entre El Escorial y Ávila en los años

12 McCullough, 2012, 28-32.

13 Siempre la contabilidad del número de muertos fue un problema pues se limitaban las estadísticas a los que fallecían en hospitales, como ocurrió durante la construcción del Canal de Panamá, en especial durante la fase francesa (López Cerezo, s. f.). Los norteamericanos calcularon en más de veinte mil el número de fallecidos en esa primera fase de construcción del Canal (década de los ochenta y noventa del siglo XIX), con tasas de mortalidad en torno al $25 \%$ (Sutter, 2000, 66). Durante la gestión norteamericana tenemos cifras en torno al 17,5 y 15,3 por mil entre los blancos y de 19,4 y 53 por mil en 1907-1908 (Ibidem, 71), cifras en las que intervenían la malaria y la fiebre amarilla, pero también la tuberculosis o la neumonía. Michael Conniff habla de unos 4.500 muertos entre los trabajadores negros durante la fase de construcción norteamericana pero, considerando que casi todos los trabajadores negros vivían fuera de la zona controlada en el Canal, la cifra podría alcanzar los quince mil muertos. (Ibidem, 85). La expansión británica por suelo africano dio lugar también a dolorosas experiencias en este ámbito (Curtin, 1985 y 1989).

14 Rodríguez Ocaña et al., 2003b, 41. 


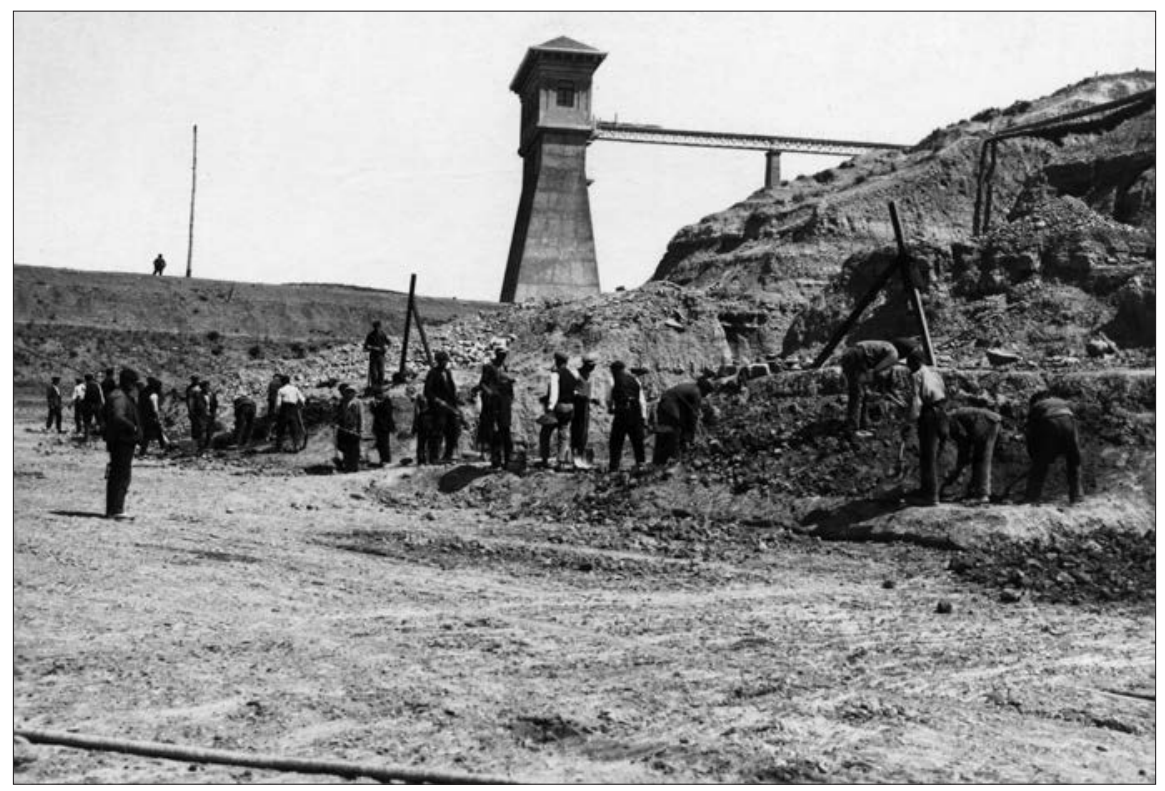

ImAGEN 4. Obras de la presa de Sotonera. Fuente: Archivo de la Confederación Hidrográfica del Ebro, reproducido de http://www.cosechadeinvierno.es/2012/03/la-sotonera-historia-deun-embalse.html.

sesenta del siglo XIX y con la construcción de un puente sobre el río Tiétar entre la toledana ciudad de Oropesa y la abulense de Candeleda, ya a finales de dicho siglo. En estos dos casos la obra pública ocasionó una exacerbación de la enfermedad palúdica pues se localizaba en zonas endémicas graves de la enfermedad en Cáceres, Toledo y Ávila, provincias colindantes. La incidencia ya de por sí grave de la enfermedad en Extremadura (1.054 fallecidos en 1900 y más de 150.000 afectados) ${ }^{15}$ se incrementaba aún más con la llegada de estos operarios que se sumaban a los obreros agrícolas que acudían a realizar tareas rutinarias y de temporada hacia esta zona, el Levante o Andalucía, para recolectar el pimiento, el arroz, los cítricos o la aceituna. ${ }^{16}$ Esta concentración de hombres se hacía aún más peligrosa con ocasión de obras propiamente hidráulicas, como ocurrió con la construcción del pantano del Zapatón (1902), Guadalmellato (1910) ${ }^{17}$ y, en el caso

15 Rodríguez Ocaña et al., 2003b, 41.

16 «El paludismo y la lucha antipalúdica en España», Ibérica, 1 de enero de 1927, XXVII, 2-6.

17 Pérez Moreda, 1986. Hauser, 1913. 
de nuestro estudio, en la Sotonera, Riegos del Alto Aragón (1917). Estas obras públicas ocasionaban una transformación ambiental que beneficiaba la propagación de los mosquitos vectores y con ello un incremento de la incidencia palúdica. Los trabajadores sanos de las obras públicas y de tareas agrícolas encontraban entornos favorables para enfermar por culpa de los vectores y de las malas condiciones de alimentación, higiene y vivienda, como ya hicieron ver los miembros de las Comisiones de Malaria del Comité de Higiene de la Sociedad de Naciones que visitaron España en 1924 y en 1931. Lo mismo ocurría con los obreros que llegaban de otras zonas endémicas de paludismo, caso de los obreros de las Indias occidentales en Panamá o de los andaluces, extremeños o del Levante español, que podían infectar a los vectores durante varios años alimentando la rueda de las infecciones y ayudando a propagar la imagen —en el caso de Panamá— de la población de color como reserva de malaria. ${ }^{18}$

\section{Iniciativas estatales en obra hidráulica y planificación sanitaria: avances en el tratamiento y profilaxis de la malaria}

Lo cierto es que la vinculación de estas concentraciones de obreros con el incremento de la incidencia palúdica no pasó desapercibida ni a los ingenieros ni a los cuerpos médicos, y en cuanto se empezó a conocer el papel que tenían los mosquitos en la transmisión del plasmodio (el periodo entre 1880 y 1900 fue especialmente crítico en este sentido) van a iniciarse los primeros tratamientos a gran escala de la enfermedad, paralelos en el tiempo al desarrollo de los grandes proyectos hidráulicos que nos ocupan.

Los avances médicos y la política sanitaria se incorporaron a la planificación hidráulica y a los procesos de construcción de las grandes infraestructuras de presas, canales y acequias. El intervencionismo del estado se concretará en varios frentes: la elaboración de normativas sanitarias en los poblamientos de obreros y en la propia obra hidráulica, la dispensación de medicamentos gratuitos, la creación de plazas médicas y sanatorios para una mejor asistencia a los trabajadores, la destrucción de mosquitos y la colaboración con instituciones y sanitarios del máximo prestigio. En el caso de Panamá, es bien conocido el empeño del presidente Roosevelt en colocar al frente de los cuidados médicos del Canal de Panamá a un médico

18 Sutter, 2005, 73. Martínez Navarro y Bernabeu-Mestre, 2009, 48-49. 
de renombre en enfermedades tropicales, como fue el caso del elegido Gorgas, ${ }^{19}$ discípulo del profesor William Henry Welch (del Johns Hopkins Medical School), luego apoyado también de forma decidida por el responsable máximo del Canal, el ingeniero John Stevens. En cuanto a España, Riegos del Alto Aragón había aprendido de la experiencia de Panamá cuando ocurrió el gran brote palúdico de 1917. Por ello, el ingeniero Severino Bello no dudó en «proponer la alta intervención técnica del Instituto Nacional de Higiene de Alfonso XIII», bajo la dirección entonces de Ramón y Cajal y la responsabilidad directa en cuestiones palúdicas del doctor Pittaluga, quien formuló —en compañía del propio Bello- el plan de campaña antipalúdica, en el que desempeñarían un importantísimo papel

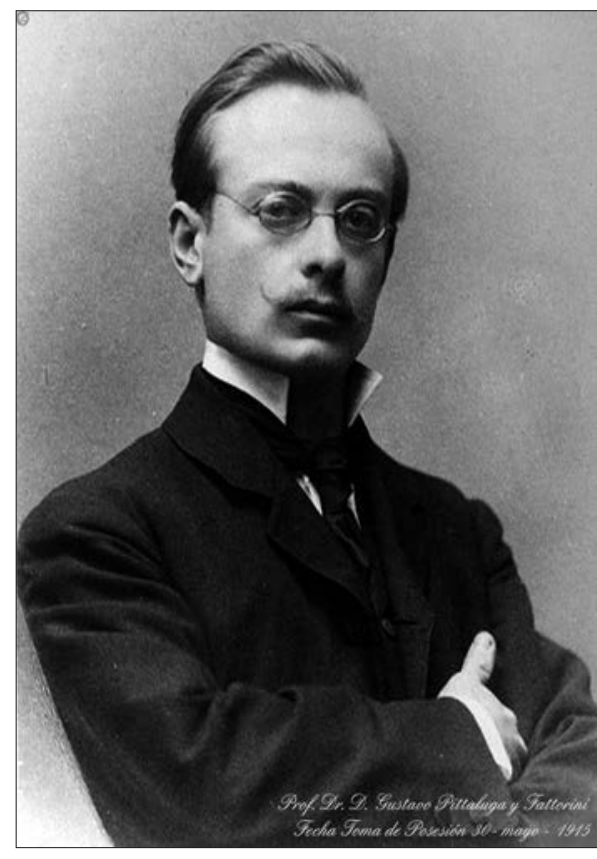

Imagen 5. Dr. Gustavo Pittaluga. Fuente: Banco de imágenes de la Real Academia Nacional de Medicina, en http://www.ban codeimagenesmedicina.com/banco-de-mage nes/cate gorias/retratos/retratos/pittaluga-yfattorini-gustavo-550.html. las brigadas antipalúdicas bajo la dirección facultativa de las obras pero coordinadas con los servicios médicos. ${ }^{20}$ Más tarde, cuando se cree la Confederación Sindical Hidrográfica del Ebro, se oficializará la creación de un Servicio Sanitario dentro de la propia Confederación (1928), que supondrá el reconocimiento tácito de lo que la experiencia en Panamá enseñó, pero también de lo que enseñó el brote epidémico de Sotonera: que la base de las tareas en el ámbito rural era la

19 McCullough, 2012, 360-361.

20 «Lucha contra el paludismo en las obras de Riegos del Alto Aragón», Revista de Obras Públicas, 23 de septiembre de 1920, I, 2348, 455, 457 y 459. El papel de las brigadas ya había sido resaltado debidamente por Ronald Ross en fecha muy temprana (1902) en su conocido folleto Las brigadas contra el mosquito y cómo organizarlas, que debía ser bien conocido por los médicos españoles. En Panamá estas brigadas contaron con el apoyo militar, en Sotonera no consta que esto fuera así, aunque sí contaron con el apoyo de la estructura organizativa de las obras en el ámbito meramente ingenieril. 
sanidad («pero base de toda campaña de esta naturaleza debe ser la sanitaria que se encomienda al nuevo servicio»). ${ }^{21}$

La publicación y difusión de los avances en la etiología del paludismo fue muy rápida, como no podía ser de otro modo. De hecho, en 1900 ya se difunden en España los avances del doctor escocés Ian Macdonald, médico de la Compañía Minera de Río Tinto, futuro doctor en París con una tesis sobre «La propagación del paludismo por los mosquitos»; ${ }^{22}$ en 1901 los doctores Huertas y Mendoza hacen lo propio en Cáceres, ${ }^{23}$ y en 1902 el doctor Pittaluga, recién llegado a España, en Cataluña, Valencia, Baleares y Madrid, año este último que coincide precisamente con la aprobación del I Plan Nacional de Obras Hidráulicas en España y con la publicación de la obra de Ronald Ross. Tanto Pittaluga como otros científicos se dieron cuenta muy pronto del enorme peligro que entrañaba la obra hidráulica por muy dirigida que esta estuviera a contener la expansión palúdica. En España, ya en 1905, se elaboran unas instrucciones para poder redactar proyectos de pantanos o presas en las que es fundamental analizar los focos palúdicos que pudieran crearse. Es por ello que muy bien puede afirmarse que el paludismo fue la razón principal de que se impulsaran los estudios de salud pública en torno a las grandes presas, permitiendo abrir líneas de investigación que hoy en día nos permiten tener un conocimiento amplio de las relaciones entre la obra hidráulica y el paludismo. ${ }^{24} \mathrm{De}$ hecho, Alberto Aguilar, quien fuera el director de los canales del Ebro, se mostró partidario siempre de que los médicos higienistas prestaran la mayor atención a las grandes obras hidráulicas y a las repercusiones sanitarias que generaban. El médico Pittaluga y las instituciones estatales parece que lo tuvieron claro una vez que la etiología del paludismo se conocía y que se abrían múltiples frentes para actuar contra la enfermedad. Pittaluga, en su trabajo «El problema del paludismo en las grandes obras hidráulicas» (1929), ya avisaba de que las obras hidráulicas incrementaban la incidencia del paludismo («un aumento transitorio del grado de difusión y de

21 Lorenzo Pardo, 1928, 1-3.

22 Fernández Astasio et al., 2011. Bueno Marí y Jiménez Peydró, 2008, 469.

23 Más tarde — en la segunda y tercera década del siglo XX-, en la zona de Navalmoral de la Mata y Talayuela, actuaron doctores de la talla de Pittaluga, Illera, Bardají, Sella y De Buen, estableciéndose laboratorios de análisis, servicio de tratamiento de enfermos, de administración de quinina, de petrolización y destrucción de Anopheles. La incidencia del paludismo aquí era la más grave de España (Bello, 1927, 150-158 y 238-253, e Ibérica, I, XV, 361-362, 36, 15-22 de enero de 1921). Al respecto, la mayor aportación actual al estudio de esta cuestión en Rodríguez Ocaña et al., 2003b.

24 Utrera Caro, 2002. Hunter et al., 1994. Ordóñez, 1984. 
intensidad de la endemia palúdica»). Algo que no era nada nuevo y que se había visto, observado y comprobado en la propia España o Panamá, y en otros países como Francia, Italia, Grecia, Rumanía, Bulgaria, Holanda o Estados Unidos, sobre todo desde finales del siglo XIX, fruto de toda una serie de factores de carácter natural, técnico y social.

La concentración de obreros en las obras públicas hidráulicas se veía acompañada por una escasa mecanización de la obra, lo cual implicaba una mayor exposición temporal de los obreros a las picaduras de los mosquitos, una más extensa convivencia en el tiempo de obreros de diferente procedencia que reactivaba la enfermedad entre ellos y con la población autóctona de la zona, una población que ya empezaba a experimentar en sus propias carnes el proceso de abandono del campo. Proceso que explicará a inicios del siglo XX también la aparición de Juntas de Reintegración al Campo, como la de Barcelona, y el intento de mejorar las condiciones de vida en el ámbito rural para dar «la sensación de que se lleva al hombre al campo como hombre, no como máquina de cultivo». ${ }^{25}$

Dentro de esta preocupación por el entorno rural hay que enmarcar las problemáticas relacionadas con el paludismo, una enfermedad eminentemente rural $^{26}$ y de la que, como ya dijimos, empezaban a conocerse los medios más adecuados para su tratamiento. Las iniciativas médicas de carácter privado no faltaron. Un buen ejemplo es la acción preventiva implementada por el doctor Macdonald en las Minas de Rio Tinto (Huelva) en 1903. Más tarde, destacamos el papel protagonista que asumió la Fundación Rockefe1 ler ${ }^{27}$ a través de la Junta de Sanidad Internacional (1916) y organismos como la Cruz Roja y la Sociedad de Naciones. En España, la llegada al país de Pittaluga con la entrada del siglo XX y la publicación en 1903 de sus Investigaciones y estudios sobre el paludismo en España, marcan un antes y un después en el tratamiento y la profilaxis de la enfermedad, marcando también las acciones tanto de organismos privados como públicos. Estos avances en la profilaxis del paludismo tuvieron como primeros beneficiados a los obreros

25 De la Fuente, 1928. González Quijano, 1915 y 1917. El intento de detener la sangría que ya se experimentaba en el campo también debió estar relacionado con el interés de que no se incrementaran las tensiones en las ciudades, aunque en vísperas de la Guerra Civil la situación de conflictividad social en algunas zonas rurales del país era enorme, Oficio al subsecretario del Ministerio de la Gobernación al gobernador civil de Lleida, Madrid, 29 de noviembre de 1941, Archivo Histórico Provincial de Lleida (AHPLL), Gobierno Civil, 1907. Sobre la zona de nuestro estudio en el Alto Aragón pueden mencionarse dos trabajos referidos a la labor de la Sección Femenina en el ámbito rural: Marías Cadenas, 2011 y Rebollo Mesas, 2003.

26 Lorenzo Pardo, 1928, 1. Pittaluga, 1928, 2.

27 Stepan, 1978. Pineo, 1990. Cueto, 1992. Parks y Nuermberger, 1943. 


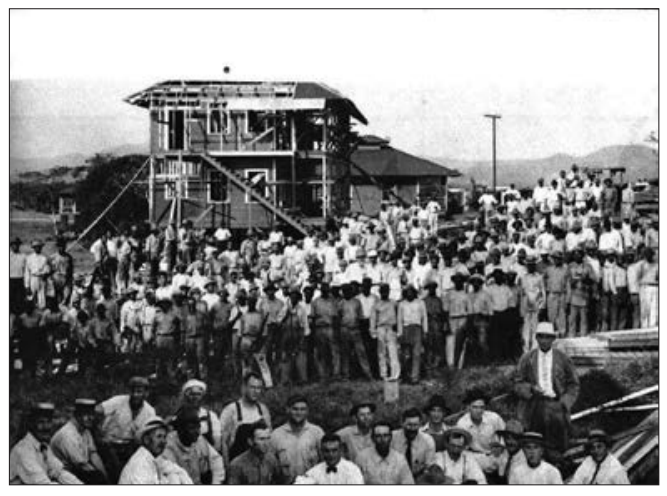

IMAGEN 6. Trabajadores blancos y de color en las obras del Canal de Panamá. Fuente: laestrella.com.pa.

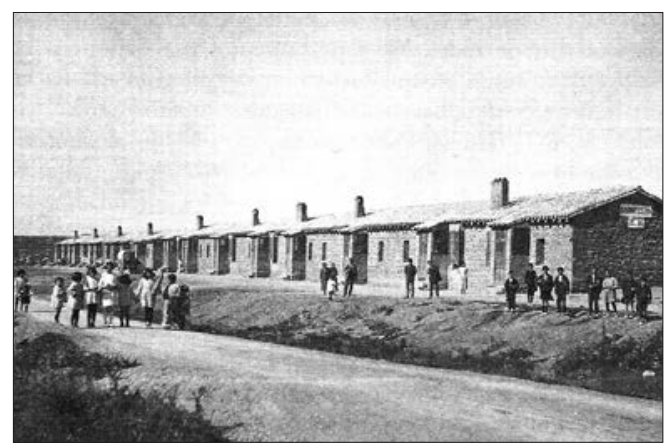

IMAGEN 7. Barriada de barracones para trabajadores sin familia en las obras de la Sotonera en 1922. Fuente: Un viaje de Ramón J. Sénder por los Riegos del Alto Aragón [1922], Comunidad de Riegos del Alto Aragón, 2001.

rurales, en tanto la planificación hidráulica adquiría más consistencia y la investigación médica lograba éxitos terapéuticos en el tratamiento antipalúdico. Esta evolución podemos irla observando a lo largo del proceso de construcción de tres de los grandes sistemas de riego ejecutados en España desde mediados del siglo XIX hasta mediados del siglo siguiente: ${ }^{28}$ el canal de Urgell y su Canal Auxiliar, el Canal de Aragón y Cataluña y el Sistema de Riegos del Alto Aragón; entre los tres abarcan casi trescientas mil hectáreas de riego pertenecientes a las comunidades de Aragón y Cataluña (provincias de $\mathrm{Za}-$ ragoza, Huesca y Lleida). El más antiguo fue el Canal de Urgell a mediados del siglo XIX, ampliado en 1932 con la construcción del Canal Auxiliar. La carencia de medidas profilácticas contra el mosquito, a mediados del XIX, no solo debió ocasionar los consabidos casos de paludismo entre los operarios y obreros de las obras hidráulicas, sino que más tarde, con la puesta en marcha del regadío en las fincas, se agravó la situación de los campesinos frente a la enfermedad al no haberse realizado tareas de drenaje y de nivelación..$^{29}$ En el Canal de Aragón

28 Doctor Beltrán, 1930. «El Dispensario Antipalúdico...», 1931. Pastor, 1931. Mateu Giral, 2005. Ramon-Muñoz, 2004. Vila i Ricart, 1992.

29 Domingo Clota, 2004. 


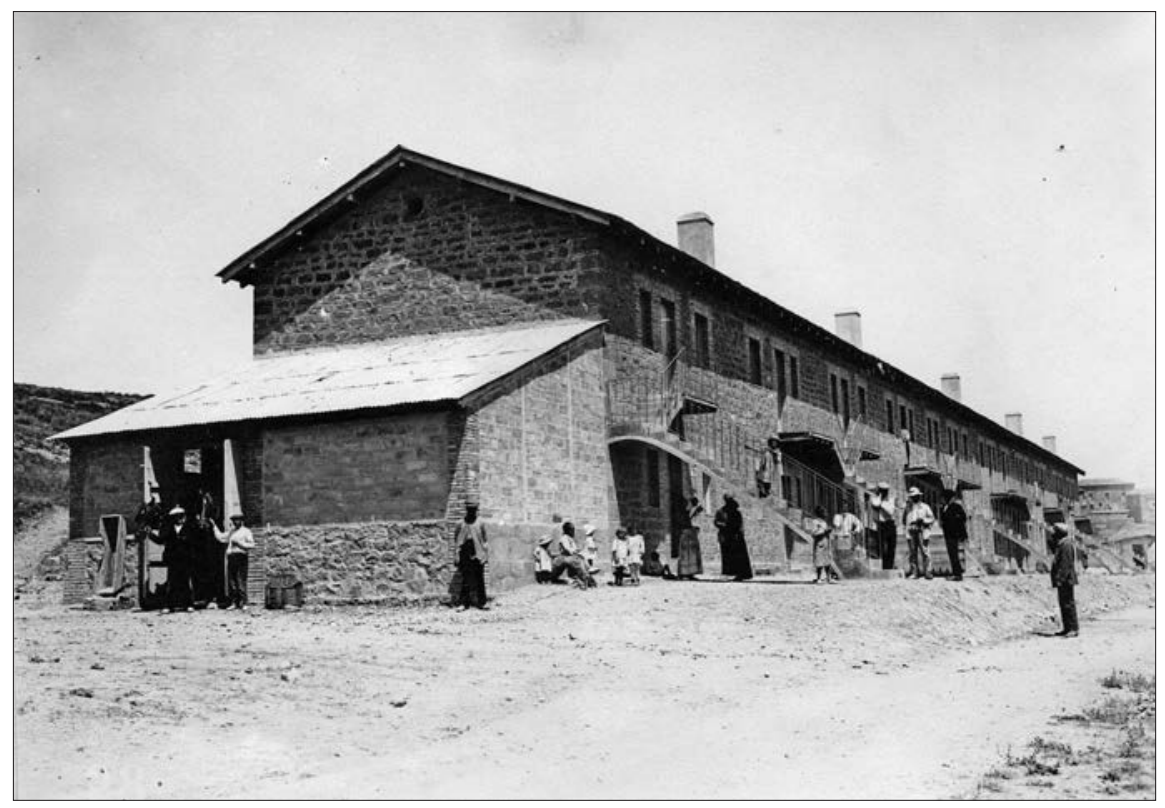

ImAGEN 8. Viviendas para trabajadores con familia en las obras de la Sotonera en 1922, Fuente: Un viaje de Ramón J. Sénder por los Riegos del Alto Aragón [1922], Comunidad de Riegos del Alto Aragón, 2001.

y Cataluña, inaugurado en 1906 por Alfonso XIII, lo que aconteció fue similar pues apenas había dado tiempo a implementar normas de prevención tras las publicaciones de los especialistas médicos que vinculaban la anegación del suelo con la propagación del mosquito y la expansión de la enfermedad palúdica: ${ }^{30}$ en consecuencia, la situación de la población rural frente al paludismo se agravó. Era otra muestra más que se sumaba a lo acontecido en la apertura del canal de riegos del Delta derecho del Ebro (1862), así como años después (ya en el siglo XX) con el canal del Delta izquierdo. ${ }^{31}$

30 La rotura de los canales era también motivo importante de preocupación por los encharcamientos que ocasionaba tanto en las propias soleras de los canales como en las fincas aledañas. Para el caso del Canal de Aragón y Cataluña, véase el trabajo de Hué Herrero y Llamas Madurga, 1960-1961, y el de Mateu González, 2015.

31 Aguilar, 1916. Cartañá Castellá et al., 1935. Fabregat Galcerà, 2009, 154. Estas circunstancias hicieron que la zona fuera incluida en los objetivos prioritarios del Servicio Técnico de Paludismo que creó la Mancomunidad Catalana, nombrando a Gustavo Pittaluga como presidente. El 28 de noviembre de 1915 el doctor italiano dio una conferencia en el Orfeó Tortosí (Ibérica, 4 de diciembre de 1915, II, IV, 101, 354), iniciando lo que algunos califican de primer intento de planificación sanitaria en España (Hervás i Puyal, 2004, 10). 


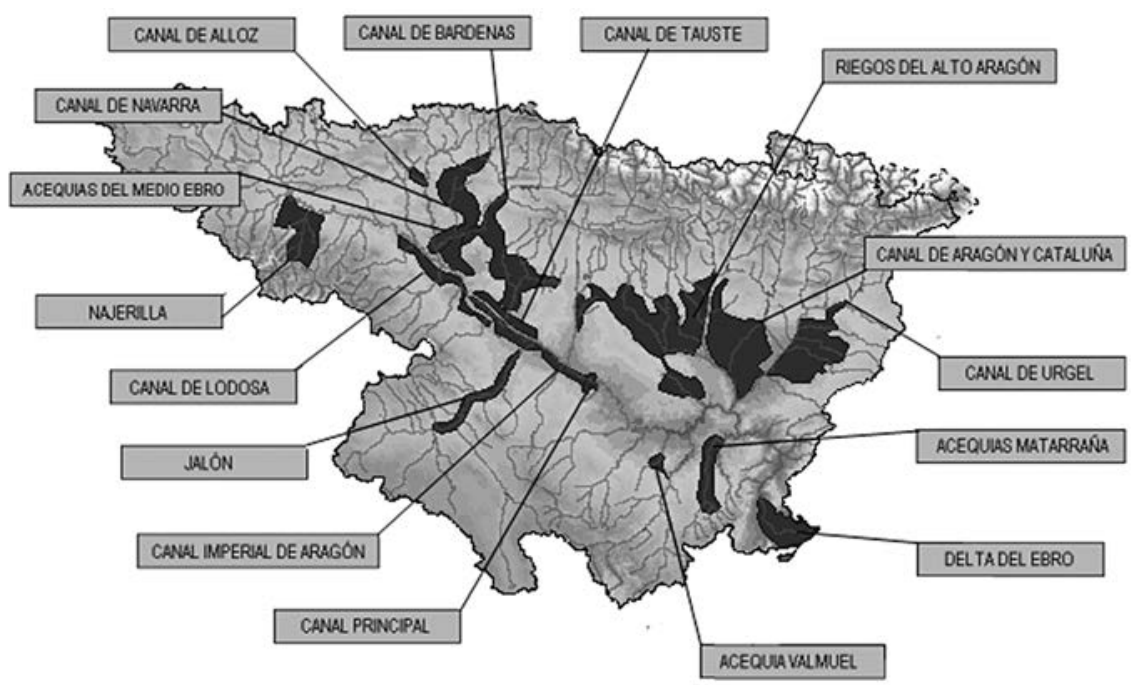

ImAGen 9. Ubicación de Riegos del Alto Aragón, Canal de Aragón y Cataluña y Canal de Urgel en la Cuenca Hidrográfica del Ebro. Fuente: Cartografía de la Confederación Hidrográfica del Ebro.

Muy pronto, en 1915, se crea el Servicio Técnico de Paludismo, bajo la dirección de Pittaluga, dependiente del Institut d'Estudis Catalans, convertido luego en el Servicio de Estudios Sanitarios (1918) y más tarde (1920) en el Servei de Sanitat de la Mancomunitat de Catalunya, dirigido también por Pittaluga, que actuó en zonas rurales del área metropolitana de Barcelona (Llobregat) y en otras más aisladas del ámbito urbano como el propio Delta del Ebro o la zona de riego del Canal de Aragón y Cataluña (localidad de Almacellas). ${ }^{32}$ Es en estos mismos años cuando se aprueba el Plan de Riegos del Alto Aragón (real orden de 1 de marzo de 1913), que supone no solo una propuesta de intervención hidráulica — la de mayor envergadura en Europa- sino también de colonización agrícola. Los temas sanitarios e hidráulicos empezarán a ir de la mano, aunque un tanto precipitados por los acontecimientos del brote epidémico de 1917 en Sotonera. Las experiencias en Río Tinto y en Cataluña, encabezadas estas últimas por Pittaluga, debieron servir para abortar el brote pues, por ejemplo, en Cataluña el Servicio Técnico de Paludismo ya había realizado encuestas epidemiológicas, había

32 Galiana y Bernabeu-Mestre, 2006, 153-155. Rodríguez Ocaña y Perdiguero, 2009, 102. Bernabeu-Mestre, 1998 y 2000. Hervás i Puyal, 2004, 5-10. Sabaté i Casellas, 1992, 222-255. 
LOS GRANDES PROYECTOS HIDRÁULICOS Y LAS POLÍTICAS ANTIPALÚDICAS

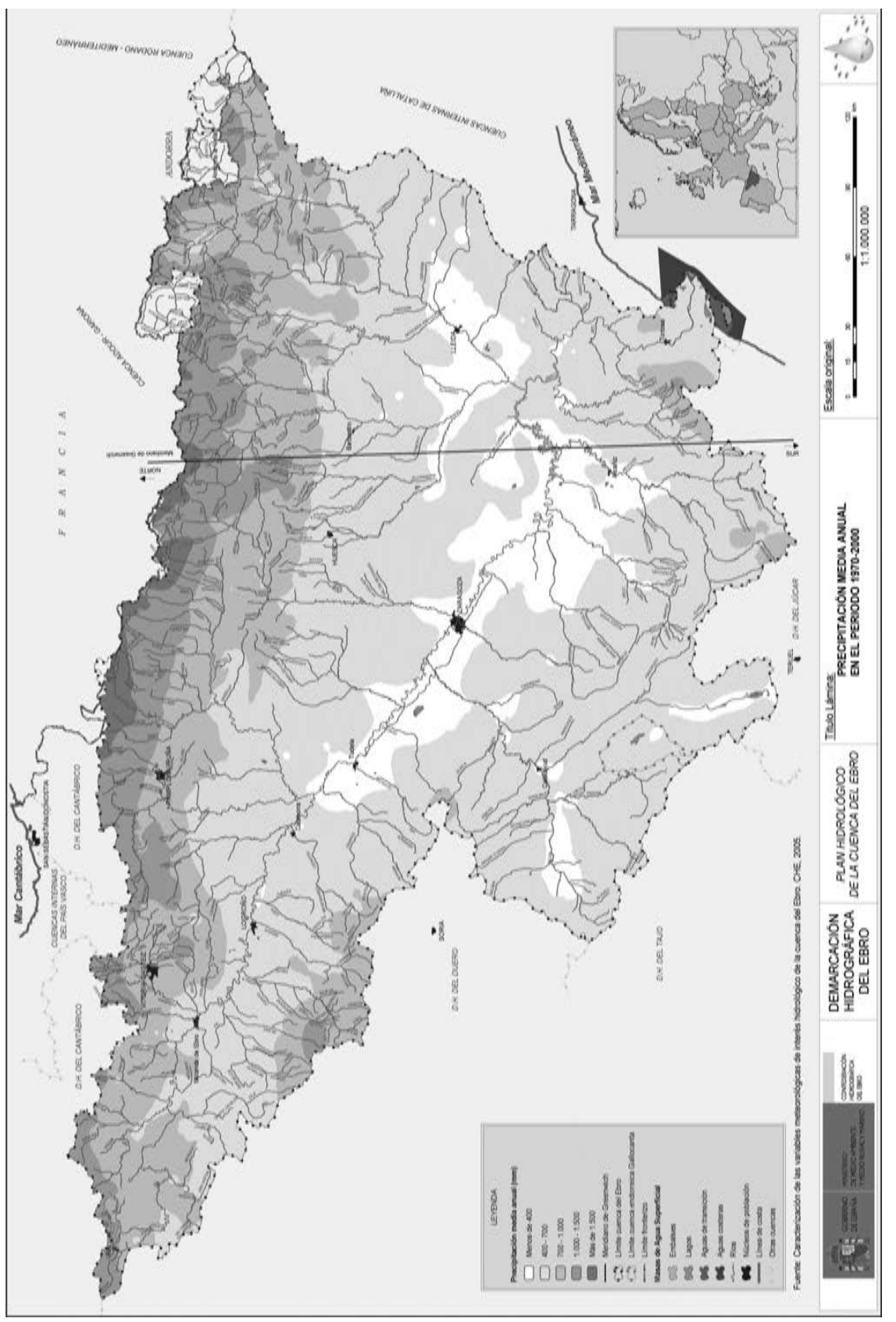

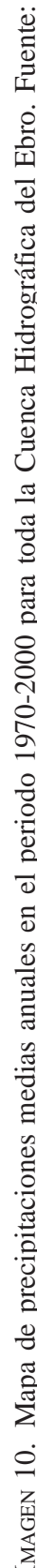


ensayado la profilaxis química y los trabajos de saneamiento, así como la creación de dispensarios antipalúdicos de carácter temporal que luego pasarían a ser permanentes como los de Amposta, el Prat y el de Almacellas, en la zona del Canal de Aragón y Cataluña (1923). ${ }^{33}$

\section{Condiciones climáticas diversas y transformaciones ambientales similares}

Con un clima tropical húmedo y una media anual de precipitaciones próxima a los $3.000 \mathrm{~mm} / \mathrm{año}$, Panamá presenta una vegetación de sabanas y bosques tropicales en las Tierras Bajas Calientes donde se ubica la zona del Canal. Se trata de un entorno propicio para el desarrollo de Anopheles: agua abundante y calor. Mientras, en la zona de los Riegos del Alto Aragón nos encontramos con un nivel de precipitaciones característico de zonas áridas o semiáridas, con oscilaciones que van desde los $350 \mathrm{~mm}$ en el centro de la Depresión del Ebro hasta los 600 mm como máximo en las zonas de los Somontanos, precipitaciones que sufren además la fuerte acción de un viento desecante como es el del norte. ${ }^{34}$ No obstante, vamos a ver cómo - pese a las diferencias climáticas y del nivel de precipitaciones existentes entre Panamá y las zonas regadas por el Sistema de Riegos del Alto Aragónla zona española tiene también condicionantes naturales que favorecen la existencia de hábitats apropiados para la reproducción del mosquito vector del paludismo. Estos condicionantes naturales se suman a los nuevos hábitats que crean tanto las obras hidráulicas como luego la instalación de fincas con riego, que al no contar habitualmente con tierras niveladas y con obras de drenaje habilitan nuevas zonas de expansión del Anopheles. Pero, como decimos, en los lugares en donde se construyen obras hidráulicas como los embalses y los canales y en aquellos otros donde se desarrolla la expansión de nuevos regadíos había antes de que llegara la obra hidráulica y el riego una incidencia palúdica previa. Para que esto se diera había condicionantes naturales como es el caso del clima, la orografía, los suelos e incluso el viento, todos ellos han favorecido la aparición de humedales, en unos casos, y de lugares para conservar y almacenar agua desde muy antiguo, por otro. Factores naturales y humanos, por tanto, han contribuido eficazmente en

33 Rodríguez Ocaña y Perdiguero, 2009, 102.

34 Cuadrat Prats, 1999. Para la cercana zona regada por el Canal de Aragón y Cataluña y sus similares niveles pluviométricos puede verse Mateu González, 2015, 70-76. 
poner medios para aliviar la escasez de agua para uso humano y animal. En el caso de Panamá los factores naturales eran muy obvios para crear hábitats húmedos, pero en el caso de las provincias de Huesca y Lleida nos encontramos con un territorio de escasas precipitaciones en el que no faltan humedales y depósitos temporales de agua próximos a las poblaciones que permitían la transmisión del paludismo incluso antes de que llegara el regadío, llegada que contribuyó más tarde a potenciar sus efectos, como es conocido por todos. Pese a las escasas precipitaciones, la zona de Riegos del Alto Aragón, al igual que las próximas zonas irrigadas por el Canal de Aragón y Cataluña y el Canal de Urgell, dispone de zonas encharcadas, de lagunas naturales endorreicas, de balsas artificiales para uso humano o ganadero, de aljibes excavados en las areniscas, de surgencias de agua en formaciones de yeso, etc. ${ }^{35}$

El origen oligocénico de estos paisajes esteparios de la Cuenca Hidrográfica del Ebro favorece la existencia de tierras con problemas de salinidad, en concreto unas trescientas mil hectáreas tienen este problema, con diferentes niveles de concentración de sales, que dependen de la profundidad, de la época del año y de otros muchos factores. Los niveles pueden alcanzar valores tan altos que imposibilitan el cultivo normal en las fincas ${ }^{36} \mathrm{o}$ disminuyen considerablemente los rendimientos agrícolas. Estas tierras cargadas de sales en las partes bajas son tierras poco permeables que favorecen el encharcamiento y el agravamiento de los problemas derivados de la concentración de sales tras la evaporación. La salinización de las fincas corre paralela a la impermeabilización del suelo y al surgimiento de múltiples lagunas, charcas o balsas de origen endorreico. ${ }^{37}$

Los problemas se agravaban con el regadío. Por ejemplo, en 1946, se había parcelado la zona destinada al arroz en la margen derecha de la Clamor Amarga (zona regada por las aguas del Canal de Aragón y Cataluña), pero los colonos se negaron a admitir más de cien hectáreas por estar encharcadas y salinizadas. Sobre el mal estado de algunas fincas da cuenta

35 Un estudio sobre la importancia de estos lugares en la actividad económica rural y en la propia vida de las poblaciones es el de L'arquitectura de l'aigua, 2004, en el que encontramos esclarecedores trabajos de Joan Rovira, Salvador Palomar, Josep Ros, Miguel Domingo Clota y Francisco Villegas i Martinez sobre los abrevaderos para el ganado, las acequias y los canales como puntos de encuentro de la población rural.

36 Lasanta et al., 2002.

37 Sin querer ser exhaustivos el endorreísmo aragonés ha sido abordado por muchos autores: Dantín Cereceda, 1942; Ibáñez, 1975; Pedrocchi Renault y Sanz Sanz, 1991. Debemos trabajos a B. L. Valero Garcés, 1999 y P. L. López et al., 1999. Asimismo, Molina Herranz y Olivera Elfau, 1987; Pedrocchi Renault et al., 1986, e Ibáñez et al., 1984. 
una solicitud de María Navarro Sanjuán (viuda de un parcelero de la finca Cuartos del Marqués, Ballobar, Huesca) renunciando a una parcela del Cuarto Boral por haber comprobado ya varios años que no era apta para el cultivo. ${ }^{38}$ Algo similar ocurría con la finca de Antonio Barés Casañé, colono de la finca Suchs, que no tuvo cosecha alguna en su primer año de cultivo (1947-1948) por problemas de salinidad y de falta de nivelación. ${ }^{39}$ En esta finca, regada con agua del Canal de Aragón y Cataluña, había en 1951 — casi medio siglo después de su inauguración — parcelas cultivadas muy salinizadas, con rendimientos escasos, que obligaba a los colonos a solicitar una rebaja en el cupo forzoso de entrega asignado a las parcelas que cultivaban en régimen de acceso a la propiedad. ${ }^{40}$ Este problema afectaba a treinta parcelas de las mencionadas fincas con una extensión entre las 5 y 16 hectáreas cada una, sumando más de trescientas hectáreas con problemas de salinización. ${ }^{41}$ La finca tenía 2.033 hectáreas, cantidad que nos habla del importante porcentaje que se encontraba en condiciones de salinidad elevada, si tenemos en cuenta que 813 hectáreas más estaban dedicadas a pastos, probablemente por incidencia de la salinización. Todavía en los años setenta del siglo XX, agricultores de Plà de la Font expresaban el peligro que suponía el encharcamiento de 40 hectáreas y su proceso de salinización. ${ }^{42}$

Esta salinización favoreció, como dijimos, la aparición de lagunas, charcas o balsas endorreicas como fueron la Laguna de Sariñena (de unas seiscientas hectáreas de ocupación) y El Basal, o casi un centenar de saladas monegrinas, hoyas y clotas del complejo Bujaraloz-Sástago, ${ }^{43}$

38 El ayuntamiento de Ballobar había expresado su interés en hacerse con las tierras de mala calidad a fin de dedicarlas a pastos pues era poco probable que otros parceleros quisieran quedarse con ellas. Oficio del jefe de la Delegación del Instituto Nacional de Colonización al Director General del Instituto Nacional de Colonización, Lérida, 22 de enero de 1949, AHPLL, Instituto Nacional de Colonización, 37.

39 Certificación del ingeniero agrónomo José Baquero de la Cruz, jefe accidental de la Delegación del Instituto Nacional de Colonización, Lérida, AHPLL, Instituto Nacional de Colonización, 47.

40 Parcelas que, en muchas ocasiones, no habían empezado a ser niveladas hasta que fueron entregadas por el Instituto Nacional de Colonización. Oficio del jefe de la Delegación del INC al jefe provincial del Servicio Nacional del Trigo de Lérida, 22 de octubre de 1951, AHPLL, Instituto Nacional de Colonización, 47.

41 Por esta razón los agricultores de la finca Suchs sembraban la cebada de forma muy espesa. Informe del ingeniero agrónomo responsable de la Delegación del Instituto Nacional de Colonización de Lérida, 4 de abril de 1946, AHPLL, Instituto Nacional de Colonización, 22.

42 Informe general de Inocencio Pardos Vicente, Pla de la Font, 14 de octubre de 1970, AHPLL, Gobierno Civil, 1929.

43 Algunas son las siguientes: El Salobral, El Saladar, La Salineta, Saladar de Agustín, Hoya de Benamud, Hoya del Mas del Rufo, Corral Viejo, Balsa de las Amargas, Plana del Vedado, Guallar, La Muerte, Camarón, Balsa Fórtiz, Rollico y Rebollón. Algunas aún sirven para que beba el ganado, en especial las que son abiertas (Los Monegros, 2006, 84 y 144-151; Agua, tierra y paisaje..., 2003, 48). 
y Peñalba-Lanaja-Castejón, La Almolda-Pallaruelo-Vallfarta y Monegri$110 .{ }^{44}$ En la zona del Urgell, ya en la provincia de Lleida, las lagunas endorreicas también abundan, caso de la laguna de Ivars de Urgel, recientemente recuperada tras haber sido declarada su desecación de utilidad pública en 1950, como otros muchos casos ampliamente estudiados, ${ }^{45}$ el Clot del Conill, el Clot de la Llacuna o el Estanyet de Vilasana. Algo similar ocurre en el Somontano oscense, en donde aprovechan los suelos arcillosos (El Tormillo, Monesma, Peralta de Alcofea o Berbegal). ${ }^{46}$

A estos humedales habría que sumar otros de diferente tipología, como es el caso de los que se originan por la acción del agua en formaciones de yeso, como la sierra de la Gessa, en el entorno de las zonas regadas por el Canal de Aragón y Cataluña. Aquí se han generado también estanques de origen kárstico aprovechando depresiones alargadas, que con las aguas de lluvia han formado la Bassa de les Piles (Albelda, Huesca) o el estanque de Queraltó (Tamarite de Litera, Huesca), que son muy relevantes por el lugar tan árido en el que aparecen. En ocasiones, estas balsas naturales se ven acompañadas de otras de origen humano que utilizan las escorrentías para ser canalizadas a través de algunos canales de piedra, caso de la balsa del Mas de los Frailes en el Bajo Cinca $^{47}$ o en los propios Monegros, en donde las canalizaciones se hacen hasta a mano (las agüeras) ${ }^{48}$ para poder facilitar el consumo de agua a los animales e incluso a los humanos, caso de la Balsa Alta, en La Almolda (Zaragoza). Estas balsas artificiales para uso humano y/o animal ${ }^{49}$ fueron habituales en medios hostiles como los estudiados. Casi todas las poblaciones catalanas y altoaragonesas regadas por el Canal de Urgell y Canal de Aragón y Cataluña tienen su «calle de La Bassa», recuerdo de lo que fue un entorno habitual e indispensable en la vida cotidiana en todas estas poblaciones de gran aridez. ${ }^{50}$ Las balsas formaban parte de la estrategia de supervivencia y debieron utilizarse desde épocas bien tempranas, desde época ibérica al menos, hasta los años sesenta del siglo XX, en especial en aquellas poblaciones más alejadas de

44 González Hidalgo et al., 1989, 143.

45 Aldomá, 2007, 205-206. Solé i Sabaté, 2007, 79-260. Alberola, 1983. Obiol Menero, 1994. Bueno y Jiménez, 2010, 699. Lemeunier, 1997.

46 Garrido Palacios, 2009, 77-80.

47 Badía Villas, 2002, 46-60 y 65-66. Bajo Cinca/Baix Cinca, 2009, 25, 32-33, 42, 59-60.

48 Los Monegros, 2006, 84.

49 Bajo Cinca/Baix Cinca, 2009, 82-83.

50 Vicedo Rius, 2009, 136. 
las corrientes fluviales. ${ }^{51}$ Hoy en día constituyen todo un patrimonio local a reivindicar y recuperar dada su relevancia para la vida rural, caso de las «balsas buenas» monegrinas en las localidades de Bujaraloz y Candasnos, y otras más pequeñas no tan integradas en el casco urbano, como la de Castejón de Monegros. ${ }^{52}$

Este tipo de recurso para el almacenamiento hídrico estuvo acompañado por la construcción de aljibes, que fueron fácilmente excavados debido a las formaciones de arenisca que acompañan a los yesos en la zona de estudio del Alto Aragón. Estos aljibes sirvieron para captar y acumular agua dulce desde la Edad del Bronce, ${ }^{53}$ localizándose en el entorno más próximo de la sierra de la Gessa, núcleo del anticlinal que arranca en las proximidades de la ciudad oscense de Barbastro y se prolonga hasta la catalana de Balaguer. Este plegamiento hizo aflorar las capas inferiores en una serie de ondulaciones formadas por yesos, inclinando capas de arcillas, calizas, margas y areniscas que estaban por encima, formando unos relieves con estratos verticales muy originales (hogbacks) ${ }^{54}$ e idóneos para excavar en las laderas de areniscas aljibes que se llenaban del agua de lluvia gracias a unos canales que recorrían la ladera y desaguaban en ellos. Estos buzamientos, que llegaban hasta los 70-80 ${ }^{\circ}$, se dan en el flanco sur de La Gessa, siendo los emplazamientos humanos más antiguos de la zona (Edad del Bronce), próximos también a cursos de agua secundarios. Las propias formaciones yesosas favorecían la aparición de algunos estanques como vimos, pero también surgencias de aguas cargadas de sales como las de la Font de Les Piles (Albelda) o la Fonteta de Carpi (Tamarite de Litera). Estas surgencias muy probablemente expliquen el origen de poblaciones al pie de la Gessa como Albelda, Tamarite, San Esteban y Almunia de San Juan pues en sus proximidades se ubican los yacimientos del Bronce más importantes de la zona. En los Monegros tenemos otras muchas fuentes, como la del Milagro y la Madre de Castejón, las surgencias o los antiguos pozos-fuente de la comarca del Somontano, caso del Pozo de Laperdiguera, de la Cabañera, Pozo Nuevo de Laluenga, etc..$^{55}$

51 Aldomá, 2007, 25. Agua, tierra y paisaje..., 2003, 28-36. L'arquitectura..., 2004, 32.

52 L'arquitectura..., 2004, 27. Pedrocchi Renault, 1988.

53 Gallart et al., 1991. Maya, 1991. Maya y Prada, 1989.

54 Belmonte Ribas, 2005, 41.

55 Garrido Palacios, 2009, 81-85 y 87-89. 
A pesar de las diferencias climáticas —no son las únicas $-{ }^{56}$ que se presentan entre el territorio panameño ${ }^{57}$ y el regado por los sistemas del Canal de Urgel, Canal de Aragón y Cataluña y Riegos del Alto Aragón, existen algunas particularidades que les son comunes. En primer lugar, en todos ellos hubo una fuerte intervención humana que generó grandes cambios ambientales y sociales en el territorio. ${ }^{58}$ Como dice Sutter, los problemas relacionados con la incidencia palúdica, en parte, eran generados por los propios ingenieros. ${ }^{59}$ Estos cambios, facilitados en unos casos por la iniciativa privada y en otros por la decidida intervención del Estado, se produjeron por la acción de una mano de obra numerosa en todos ellos, procedente de áreas de la zona, pero sobre todo de fuera de la misma. En algunos casos, como el del Canal de Panamá, la mano de obra fue mayoritariamente extranjera, tanto en la fase de construcción francesa como en la norteamericana, contribuyendo esta circunstancia - al igual que las transformaciones ambientalesa un agravamiento de las repercusiones que provocaron entre la población trabajadora y no trabajadora enfermedades como la malaria o la fiebre amarilla. El abordaje de la política sanitaria junto a la política hidráulica y de la obra pública se demostró en el Canal de Panamá y en el Plan de Riegos del Alto Aragón como fundamentales para que las obras pudieran concluirse. ${ }^{60}$

56 Con su indudable repercusión en los cursos de agua y vegetación, la zona del Canal de Aragón y Cataluña, Urgell y Riegos del Alto Aragón, que comprende comarcas oscenses y leridanas como La Llitera, Bajo Cinca, Cinca Medio, Monegros, Somontano, Noguera, Segrià o Pla de Urgell, destaca por su vegetación adaptada al calor, la sequía y elevada insolación, siendo mayormente halófita y gipsófila. Podemos destacar como típicas la coscoja (Quercus coccifera) — de las pocas vegetaciones arbóreas que se dan-, el taraje (Tamarix), romero (Rosmarinus officinalis), sauce (Salix viminalis), artemisia (Artemisia glutinosa), barrilla (Salsola vermiculata), saladillo (Atriplex glauca), sargadillo (Suaeda fruticosa), sosa negra (Suaeda altisima), salicornia (Salicornia herbacea), la sapera (Frankenia pulverulenta), tomillo falso (Eruca versicaria), caña o cañizo (Phragmites comunis), caña verde (Arundo plini), la retama blanca (Genista aphaerocarpa), la efedra (Ephedra vulgaris) o el esparto basto (Ligaeum spartium). Véase un estudio detallado del ecosistema monegrino -el más extremo por su aridez y salinidad de la zona de Riegos del Alto Aragón—y de su vegetación en Conesa et al., 2011.

57 Jaén Suárez, 1981. Castro Herrera, 2006.

58 Martínez de Pisón, 1984. Ibarra Benlloch y de la Riva Fernández, 2003. Sutter, 2000 y 2005. Jaén Suárez, 1990.

59 Sutter, 2000, 63-64.

60 Después de la propia construcción de las infraestructuras era fundamental cubrir puestos de médicos en las zonas que se colonizaban. Estos médicos tenían, entre otras funciones, las de «hacer el estudio del problema del paludismo en esta zona, comprendiéndose en él la vigilancia seriada de enfermos, extracciones de sangre, análisis parasitológicos, vigilancia de la medicación antipalúdica, remisión periódica de artes sobre el estado de la endemia palúdica en la zona a su cargo, proponiendo las medidas que estime oportunas para la disminución de las cifras de morbilidad y mortalidad por dicha enfermedad». Contrato de Servicio Médico dirigido al Sr. D. Melchor Gómez Sánchez, Dirección General del Instituto Nacional de Colonización, 20 de febrero de 1945, AHPLL, Instituto Nacional de Colonización, 32 . 
Tanto en uno como en otro caso, abordar los problemas que conllevaban enfermedades como las mencionadas, las dos transmitidas por mosquitos, y la consiguiente mejora de la salud pública fueron elementos básicos y fundamentales de los éxitos constructivos. La lección se aprendió, sobre todo, en la fase norteamericana de construcción del Canal de Panamá (19041914), pues pudo aplicarse en esta etapa todo lo aprendido durante la construcción del ferrocarril transoceánico y en la primera fase (la francesa) de construcción del Canal. Estas experiencias se enriquecieron (obviamente) con los avances del conocimiento sobre la malaria y la fiebre amarilla que, desde fines del siglo XIX, no dejaron de crecer de forma muy acelerada, coincidiendo con el momento de construcción del Canal. Es cierto que ya desde los años ochenta del siglo XIX el médico cubano Finlay habló sobre el posible papel del Aedes aegypti en la transmisión de la fiebre amarilla y que un protozoo estuviera en el origen de la malaria, pero hasta 1898 no descubre Ronald Ross el papel del Anopheles en la transmisión de esta última.

Todo parecía encajar en estos años para que pudiera plantearse una acción sanitaria previa a la construcción del Canal por parte de los norteamericanos. Y cuando decimos todo es todo, pues incluso el ingeniero Stevens y el doctor Gorgas fueron capaces (eso sí, con el apoyo económico y moral del gobierno norteamericano) de articular una campaña médica que podía ser ya más eficaz que durante la gestión francesa de las obras, en la que la teoría miasmática lo inundaba todo, aportando muy pocas soluciones prácticas para la gestión de las obras. Gorgas, además, era un doctor con amplia experiencia en política sanitaria en América Latina. Ya en 1901 dirigió el primer plan para acabar con la fiebre amarilla en La Habana tras la entrada de Estados Unidos en la isla de Cuba, ${ }^{61}$ aplicando una serie de medidas que luego puso en marcha en la vecina Panamá, tras convencer a su país de que si querían acabar las obras del Canal había que tomar antes medidas sanitarias.

La adopción de medidas protectoras para la población fue la tónica de Gorgas tanto en su proceder contra los mosquitos (desecación de charcas, utilización de aceite en cisternas y otros depósitos de agua, fumigaciones en viviendas, protección de las mismas con cierres en ventanas y puertas) como al crear y controlar una fuerza de trabajo básicamente no blanca ${ }^{62}$ y al emprender medidas de higienización y mejora de las condiciones de vida

61 Sirva como contraste el plan de saneamiento de la ciudad española de Cartagena (1897) de Francisco Ramos Bascuñana, Pedro García Faría y Francisco Oliver, en el que las teorías miasmáticas seguían presentes con toda su fuerza. Revista de Obras Públicas, Madrid, 30 de diciembre de 1897, II, 27, 696-703.

62 Sutter, 2005, 75. 
(alcantarillado, pavimentación y conexión de agua corriente a las viviendas). ${ }^{63}$ Toda una estrategia que estaba llena de elementos racistas que se vislumbraban en la puesta en marcha de estas medidas, aunque no dejaran de conseguir logros evidentes como fue la erradicación de la fiebre amarilla (en 1905) y la reducción de los casos de malaria. ${ }^{64}$ Con todo, entre los afroantillanos las medidas no se implementaron con igual esmero al tener esta población un carácter más rural, por lo que siguieron manteniendo altas tasas de mortalidad por malaria y también por neumonía. ${ }^{65}$ Esto es lo que ha llevado a algunos autores como Sutter ${ }^{66}$ a destacar que Estados Unidos lograra responder a los retos de las enfermedades que entrañaba la construcción del Canal de un modo efectivo pero desigual.

Mucho se ha escrito acerca del pensamiento y discurso europeo sobre los trópicos, de larga trayectoria en el tiempo y en la historia de la expansión del Viejo Continente por áreas tropicales desde la Antigüedad, ${ }^{67}$ un discurso que se nutría de la teoría miasmática hasta la propia fase de construcción del Canal por los franceses. Esta teoría tuvo larga vida pues, incluso cuando se descubrió el papel de los mosquitos en la propagación de la enfermedad, persistió la idea de que la naturaleza seguía siendo culpable al ser en ese entorno específico del trópico en donde se reproducían los mosquitos, ${ }^{68}$ afirmación que era una forma de reconocer todavía que el ambiente era el causante de las enfermedades tropicales y ocultar o negar que era producto de los cambios ambientales causados por la propia construcción del Canal, como hiciera ver Jennings, así como los funcionarios de sanidad Le Prince y Orenstein ${ }^{69}$ en su Mosquito Control in Panama.

Tanto en el caso de Panamá como en las obras posteriores del embalse de Sotonera, quedaba claro que además de las condiciones ambientales (más evidentes en Panamá que en el Alto Aragón) tenían un gran peso las alteraciones de las condiciones del suelo por excavaciones o rellenos, los deslizamientos de tierras que alteraban las condiciones hidrológicas, la llegada a los

63 López Cerezo, s. f.

64 Ibidem. Para el caso español pueden verse los trabajos de Rodríguez Ocaña et al., 2003 a y b, en los que los autores resaltan que «la intervención médica se enfocó preferentemente hacia la protección de la minoría ocupante» (Rodríguez Ocaña et al., 2003a, 42). Las noticias al respecto se recogían en revistas como Ibérica, 9 de octubre de 1920 (2, XIV, 347), 212, y 5 de febrero de 1921 (1, XV, 364), 84.

65 López Cerezo, s. f.

66 Sutter, 2005, 67.

67 Ibidem, 68. Un estudio clásico sobre la medicina tropical como arma científica del colonialismo es el de Worboys y Manson, 1988.

68 Sutter, 2005, 71-72, 80, 84.

69 Ibidem, 80-83. Sutter, 2000, 88. 
niveles freáticos que facilitaba los almacenamientos de agua en superficie, las zanjas de drenaje mal mantenidas, los dragados de lodo que generaban al secarse grietas en el suelo ideales para la propagación de los mosquitos, etc. En el ámbito de las obras hidráulicas, el papel de los habitantes de las zonas tropicales era también destacado por la teoría miasmática. De hecho, se asumía que por su propia naturaleza eran más resistentes a las fiebres (paradójicamente, se les tildaba de inferiores fisiológicamente hablando) aunque no se les acusaba de ser los causantes de las enfermedades, algo que ocurriría cuando se descubriera el papel de los vectores ya que, a partir de ese momento, se asume que tanto la malaria como la fiebre amarilla necesitaban una «reserva de cuerpos infectados» para verse afectados los que no eran inmunes. ${ }^{70}$ Se había pasado de una naturaleza responsable a la idea de que la población autóctona era la fuente de la enfermedad, lo cual facilitó mucho las políticas de segregación impulsadas por Estados Unidos, ${ }^{71}$ medidas que tenían que ver con el conocimiento que tenían de la enfermedad Mason o Carter. Otros, como Ross, no estaban muy convencidos de la necesidad de la segregación sanitaria ${ }^{72}$ y pensaban en una política de salud pública más global, como la estrategia sanitaria adecuada, ${ }^{73}$ pues las políticas de segregación suponían - en el fondo- una desigualdad evidente en la alimentación y en la vivienda, así como una mayor exposición de la mano de obra negra antillana a las condiciones favorables para contraer la malaria. ${ }^{74}$

Todo este debate de la tropicalidad en Panamá y del discurso imperialista referido a Estados Unidos ${ }^{75}$ y su expansión americana y asiática carece de sentido en el caso de los planes de riego en el Canal de Urgell, Canal de Aragón y Cataluña y Riegos del Alto Aragón. ${ }^{76}$ Ubicados los tres sistemas de riego en las actuales comunidades autónomas españolas de Cataluña y Aragón, y siendo fruto de las iniciativas privadas (los dos primeros) o del Estado (los terceros), enfrentan también una realidad climática muy distinta a la

70 Sutter, 2005, 72.

71 Ibidem, 73.

72 Araúz y Pizzurno, 2003.

73 Sutter, 2005, 73-75.

74 Ibidem, 74. En las obras de Sotonera se sabía claramente que la acción del hombre agravaba las condiciones sanitarias y ello facilitó pocos años más tarde la creación del Servicio Sanitario dentro de la Confederación Hidrográfica del Ebro.

75 Hogan, 1986. Frenkel, 2004.

76 En España, estos planes de riego tienen más que ver con la lucha contra la despoblación agrícola que empezaba a generar conflictos laborales en las ciudades (Del Arco, 1928). No ocurre lo mismo en el caso de las campañas médicas españolas en sus posesiones africanas, en donde funcionaron como instrumentos coloniales, contribuyendo — de paso - a construir entidades raciales. 


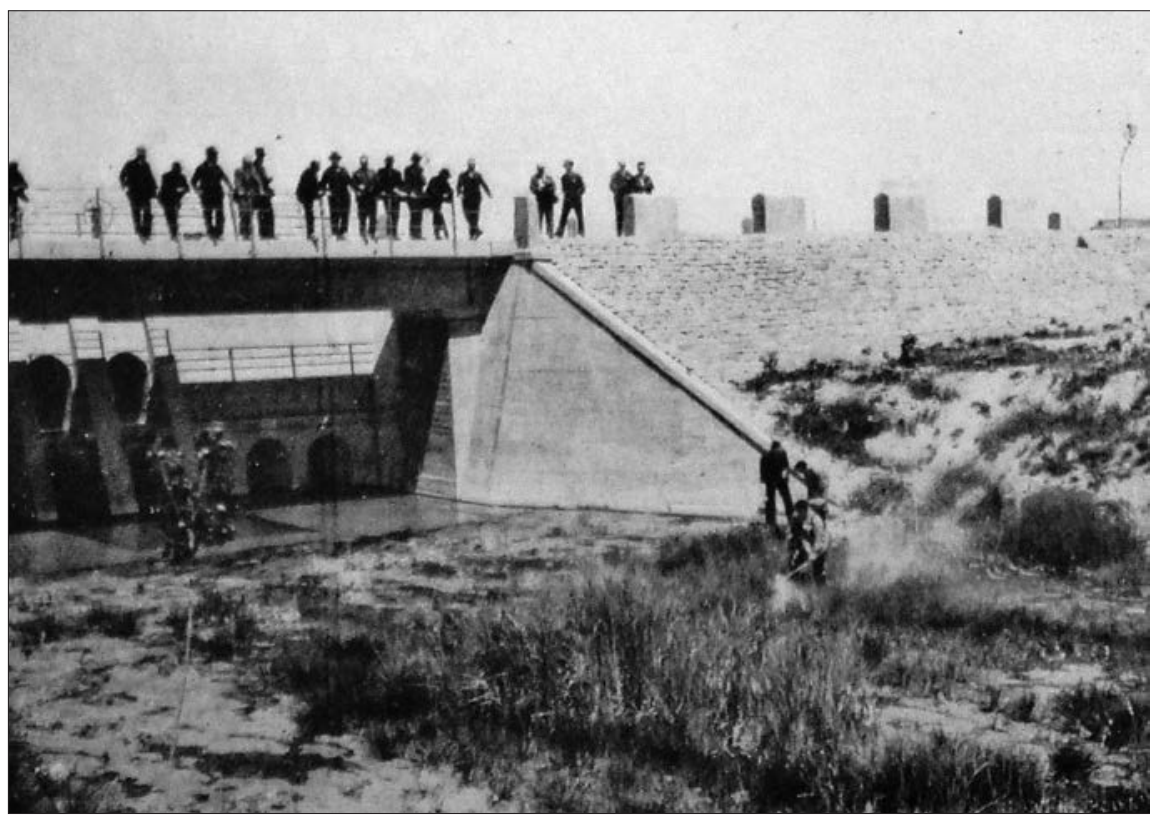

ImAGEN 11. Lucha antilarvaria en las obras de Riegos del Alto Aragón (Almudévar, barranco de las Pilas). Fuente: Confederación Sindical Hidrográfica del Ebro, 35, mayo de 1930.

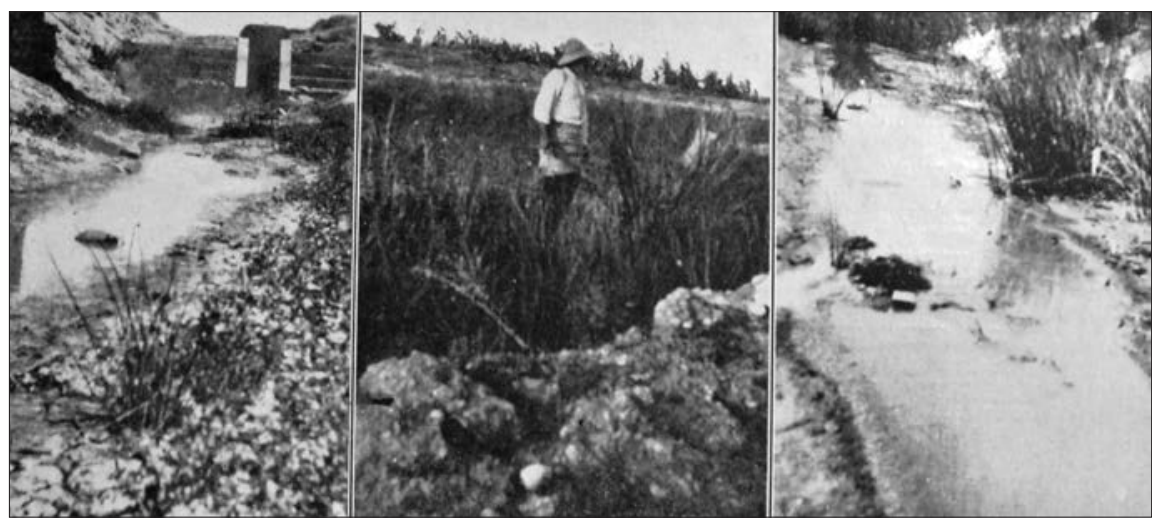

Imagen 12. Revisión de lugares palúdicos en los cauces del río Sotón y del Barranco de Puipullín en las obras de Riegos del Alto Aragón. Fuente: Confederación Sindical Hidrográfica del Ebro, mayo de 1930. 
panameña al estar caracterizada la zona de estudio española por escasas precipitaciones y estaciones muy marcadas por la continentalidad, con grandes contrastes térmicos entre el verano y el invierno. La casuística con Panamá en este ámbito físico es bien diferente entonces, diferencias que podemos entrever en otros ámbitos también: en el Canal apreciamos una gran concentración de obreros (a fines de 1904 ya había más de tres mil, pasando a más de veinte mil en 1907) $)^{77}$ y unas considerables actuaciones sobre el medio ambiente, concentradas todas ellas en muy pocos años, mientras que en las obras de los riegos españoles estas se dilatan en el tiempo mucho más y actúan sobre un territorio mucho más amplio si consideramos las zonas nuevas afectadas por el regadío pues a la obra hidráulica en sí misma considerada habría que añadir las repercusiones propias de la puesta en funcionamiento de regadíos (casi trescientas mil hectáreas en la fase final de los tres sistemas de riego) que plantearán problemas sanitarios añadidos tras acometerse las grandes obras de los pantanos (Sotonera y Ardisa, sobre todo), los canales y acequias. Mientras que el Canal de Panamá supuso un grave problema sanitario durante el proceso de construcción, en el caso de España se derivan dichos problemas del hecho de poner en marcha sistemas de riego sin haber acometido previamente labores de drenaje ni tareas de nivelación en las fincas. ${ }^{78}$

En todo caso, sí que hubo momentos puntuales en los que se dio un incremento del número de afectados por malaria, coincidiendo sobre todo con el inicio de la construcción del embalse de Sotonera en $1917,{ }^{79}$ en el que había ya mil obreros trabajando a principios de 1918. Este fue considerado el primer brote grave de malaria en España vinculado a una obra hidráulica a pesar de que la zona en la que se construye tiene apenas 400-500 $\mathrm{mm}$ al año de precipitaciones. El Plan de Riegos del Alto Aragón incluía la construcción de dos importantes presas conectadas, la de Ardisa, sobre el río Gállego, y la de Sotonera, que recogía las aguas del Sotón, Astón y Gállego, aguas estas últimas que llegaban a través de la presa de derivación

77 Araúz y Pizzurno, 2003, 107 y 111.

78 Uno de los primeros objetivos del Servicio Agronómico de la Confederación Hidrográfica del Ebro fue iniciar concursos de maquinaria agrícola para nivelación y apertura de zanjas. Este fue el caso del Concurso celebrado en Tardienta, Huesca, en noviembre de 1927 (Cruz Lapazarán, 1927). Los problemas fueron haciéndose más complejos con el paso del tiempo, como se deja ver en la «Memoria de la campaña de primavera, verano y otoño de lucha antipalúdica» del médico del Instituto Nacional de Colonización en Gimenells y Suchs (Lleida) en 1946, AHPLL, Instituto Nacional de Colonización, 22.

79 En realidad, las obras empezaron en 1915 con solo obreros de la zona, pero en el verano de 1917 se incorporaron muchos levantinos y parece que esta fue la causa del brote, con una incidencia que debió estar en torno a un $39 \%$ de los obreros de algunos núcleos, aunque no se recogieron estadísticas fiables (Revista de Obras Públicas, Madrid, 23 de septiembre de 1920, I, 2348, 455-464). 
ya mencionada de Ardisa, ${ }^{80}$ así como el pantano de Mediano en aguas del río Cinca. En este sentido, la construcción del Canal de Panamá en el ámbito tropical del istmo centroamericano tuvo un componente más puntual desde el punto de vista cronológico y las obras de los sistemas de riego del Alto Aragón uno mucho más prolongado en el tiempo, pues no solo suponen la construcción de una obra hidráulica de la relevancia que tuvo la Sotonera y las canalizaciones subsiguientes, sino que en el ámbito del desarrollo del paludismo tuvo toda una serie de ramificaciones hacia las zonas recientemente irrigadas, cuyas repercusiones en el tiempo serán mucho más amplias y dilatadas que las derivadas directamente de la construcción de las grandes infraestructuras panameñas o de las propias infraestructuras de riego en las comunidades actuales de Aragón y Cataluña. A finales del siglo XIX se reconocía que después de un siglo el Canal Imperial regaba la mitad de su zona regable y el Canal de Urgell tras veinticinco años regaba solo una tercera parte ${ }^{81}$ La incapacidad económica de los propietarios retrasó el incremento rápido de la superficie regada, aunque algunos municipios tuvieron una actitud destacada en la construcción de las acequias de distribución y el Estado franquista alentara la política colonizadora de grandes zonas en la comarca del Segrià regada por el Canal de Aragón y Cataluña. ${ }^{82}$

\section{TABLA 1}

SUPERFICIE REGADA Y VOLUMEN DE AGUA SUMINISTRADA EN EL CANAL DE ARAGÓN Y CATALUÑA, 1906-1927

\begin{tabular}{|c|c|c|}
\hline Año & Superficie suscrita $(\mathrm{ha})$ & Volumen agua suministrada $\left(\mathrm{m}^{3}\right)$ \\
\hline 1906 & 5.988 & 1.876 .484 \\
\hline 1910 & 29.031 & 42.855 .636 \\
\hline 1915 & 57.556 & 154.715 .462 \\
\hline 1920 & 63.000 & 207.840 .655 \\
\hline 1925 & 69.320 & 244.014 .955 \\
\hline 1927 & 73.356 & 297.918 .991 \\
\hline
\end{tabular}

Fuente: Confederación Hidrográfica del Ebro, 1928 (Mateu González, 2015, 416).

80 Los riegos del Alto Aragón (Primera parte). La Sotonera, historia de un embalse, documental dirigido por Eugenio Monesma, Pyrene, 2008.

81 Mateu González, 2015, 280. Ramon-Muñoz, 2013, 48-50, aporta datos de cómo evolucionó la superficie nivelada, saneada y los km de zanjas.

82 Mateu González, 2015, 387, 415-416, 433-434 y 449. 


\section{TABLA 2}

\section{SUPERFICIE REGADA Y VOLUMEN DE AGUA SUMINISTRADA EN RIEGOS DEL ALTO ARAGÓN}

\begin{tabular}{|l|c|c|}
\hline Año & Superficie regada $(\mathrm{ha})$ & Volumen suministrado $\left(\mathrm{hm}^{3}\right)$ \\
\hline 1929 & 649 & 1.947 \\
\hline 1940 & 11.599 & 34.797 \\
\hline 1950 & 21.650 & 36.995 \\
\hline 1960 & 31.934 & 63.303 \\
\hline
\end{tabular}

Fuente: Riegos del Alto Aragón. Evolución de la superficie regable, disponible en http://riegosaltoaragon.es/sistema-regable/historia/evolucion-de-la-superficie-regable/ [consultado: 03/11/2017].

En Panamá y España vamos a encontrar, eso sí, grandes transformaciones ambientales fruto de las obras emprendidas, una gran concentración de trabajadores de diferentes procedencias tanto en las obras propiamente dichas como de colonos en los nuevos regadíos, todo ello acompañado de un entorno territorial en el que — en mayor o menor grado — el paludismo tenía ya presencia antes de acometerse las obras en cuestión. ${ }^{83}$ Como diría Sutter, la introducción de una fuerza de trabajo numerosa, unida a los cambios ambientales que llevaba aparejados la obra hidráulica, exacerbaron los problemas derivados del paludismo al proporcionar a los Anopheles material inflamable en forma de humanos carentes de inmunidad o que llegaban a las zonas de obras afectados con la malaria sin presentar síntomas externos de la enfermedad endémica en sus lugares de origen. ${ }^{84}$

Recibido el 15 de noviembre de 2017 Segunda versión el 19 de febrero de 2018 Aceptado el 18 de abril de 2018

83 Severino Bello afirmaba, refiriéndose a la zona de la Sotonera, que figuraba «entre los lugares españoles que padecen paludismo de forma leve en casos frecuentes» (Revista de Obras Públicas, 23 de septiembre de 1920, I, 2348, 455).

84 Sutter, 2000, 85. 


\section{Referencias bibliográficas}

Agua, tierra y paisaje. Complejidad y diversidad en el territorio de Riegos del Alto Aragón, Zaragoza, Comunidad General de Riegos del Alto Aragón, 2003.

Aguilar, Alberto, «El paludismo en el Delta del Ebro», Ibérica, II, VI, 138, Roquetes, Tarragona, 19 de agosto de 1916, 121-124.

Aldomá, Ignasi, La lluita per l'aigua a Catalunya. De l'ús i abús a la gestió integral (1900-2007), Lleida, Pagès editors, 2007.

Araúz, Celestino Andrés y Pizzurno, Patricia, «La construcción del Canal de Panamá, 1904-1914», Mesoamérica, 45, Nueva Orleans, 2003, 100-130.

Badía Villas, David (coord.), Itinerarios naturalistas por el Bajo Cinca, Zaragoza, Ediciones Prames, 2002.

Bajo Cinca/Baix Cinca, Zaragoza, Gobierno de Aragón-Sodemasa-Prames, 2009.

Ballesteros García, Rosa María, «Luis Bello y su viaje por las escuelas de Toledo», Docencia e Investigación, 31, 16, Toledo, 2006, 21-44.

Bello, Luis, Viaje por las escuelas de España. Extremadura, vol. 3, Madrid, Espasa Calpe, 1927.

Belmonte Ribas, Ánchel, El paisaje altoaragonés. Una aproximación desde la geología, Huesca, Instituto de Estudios Altoaragoneses, 2005.

Bernabeu-Mestre, Josep, «Cultura, ciencia y política. La lucha antipalúdica de la Cataluña de la Mancomunidad, 1914-1925», Medicina e Historia. Revista de Estudios Históricos de las Ciencias Médicas, 73, Barcelona, 1998, 1-16.

Bernabeu-Mestre, Josep, «Epidémia i control social. A propósit de les campanyes antipalúdiques a la Catalunya contemporánia (1902-1925)», en de la Fuente Cullel, Pere; Puig Aguilar, Roser y Batlló Ortiz, Josep, Actes de les V Trobades d'Història de la Ciència i de la Tècnica, Barcelona, Societat Catalana d'Història de la Ciència i de la Tècnica, 2000, 37-41.

Bueno Marí, Rubén y Jiménez Peydró, Ricardo, «Malaria en España: aspectos entomológicos y perspectivas de futuro», Revista Española de Salud Pública, 82, 5, Madrid, 2008, 467-479.

Bueno Marí, Rubén y Jiménez Peydró, Ricardo, «Crónicas de arroz, mosquitos y paludismo en España: el caso de la provincia de Valencia (s. XVIII-XX)», Hispania, LXX, 236, Madrid, 2010, 687-708.

Cartañá Castellá, P.; Canicio García, I. y Fábrega Huga, J., «Resumen de la campaña antipalúdica realizada en el Delta del Ebro desde el año 1925 al 1932», Revista de Sanidad e Higiene Pública, 8, 2, Madrid, 1935, 113-165.

Castro Herrera, Guillermo, «El Istmo en el mundo. Elementos para una historia ambiental de Panamá», Signos Históricos, 16, México, 2006, 152-183.

Conesa Mor, Josep Antoni, Castañeda del Álamo, Carmen y Pedrol Solanes, Joan, Las saladas de Monegros y su entorno. Hábitats y paisaje vegetal, Zaragoza, Consejo de Protección de la Naturaleza de Aragón, 2011. 
Cruz Lapazarán, J., «Una iniciativa de la Confederación», Confederación Sindical Hidrográfica del Ebro, 6, Zaragoza, diciembre, 1927, 1-4.

Cuadrat Prats, J. M., El clima de Aragón, Zaragoza, CAI, 1999.

Cueto, Marcos, «Sanitation from above: Yellow Fever and Foreign Intervention in Peru, 1919-1922», The Hispanic American Historical Review, 72, 1, Durham, 1992, 1-22.

Curtin, P. D., «Medical Knowledge and Urban Planning in Tropical Africa», The American Historical Review, 90, 3, Washington D. C., 1985, 594-613.

Curtin, P. D., Death by Migration. Europe's Encounter with the Tropical World in the Nineteenth Century, New York, Cambridge University Press, 1989.

Dantín Cereceda, Juan, «Distribución y extensión del endorreísmo aragonés», Estudios Geográficos, 3, 8, Madrid, 1942, 505-595.

De la Fuente Pertegaz, P., «La repoblación del campo», Confederación Sindical Hidrográfica del Ebro, Revista mensual, 12, Zaragoza, junio, 1928, 17-18.

Del Arco, R., «Colonización y repoblación», Confederación Sindical Hidrográfica del Ebro, Revista mensual, 8, Zaragoza, febrero, 1928, 12-14.

Doctor Beltrán, «Estudio epidemiológico de la zona del Canal de Urgel (Extracto del)», Servicio Sanitario, Zaragoza, Publicaciones de la Confederación Sindical Hidrográfica del Ebro-Imprenta Editora Gambón, 1930, 118-124.

Domingo Clota, Miquel, «Entorn del Canal d'Urgell», L'arquitectura de l'aigua, Lleida, Pagès editors, 2004, 101-109.

«El Dispensario Antipalúdico de La Melusa», Confederación Sindical Hidrográfica del Ebro, 47, Zaragoza, 1931, 19.

Fabregat Galcerà, Emeteri, «La colonización del delta del Ebro: de la barraca a los núcleos urbanos (s. XII-XX)», en Bolòs, Jordi y Vicedo, Enric (eds.), Poblament, territorio i Història Rural, Lleida, Institut d'Estudis Ilerdencs-Diputació de Lleida, 2009, 139-160.

Fantini, Bernardino, «Las estrategias de la lucha antimalárica antes de la Segunda Guerra Mundial», en Nájera Morrondo, José Antonio y González Bueno, Antonio (coords.), Malaria: exposición celebrada en la Biblioteca Nacional del 17 de marzo al 7 de junio de 2009, Madrid, Biblioteca Nacional, 2009, 67-78.

Fernández Astasio, Balbina; Fernández Pérez, Joaquín; Fonfría, José y Jiménez Artacho, Cristina, «El paludismo en Huelva: las investigaciones de J. Macdonald en la Rio Tinto Company», en Cobos Bueno, José M.; Pulgarín Guerrero, Antonio y Ausejo, Elena (eds.), X Congreso de la Sociedad Española de Historia de las Ciencias y de las Técnicas. Encuentro Internacional Europeo-Americano, Badajoz, SEHCYT, 2011.

Frenkel, Stephen, «Historias de la jungla. Representaciones norteamericanas del Panamá tropical», Tareas, 117, Panamá, 2004, 97-118.

Galiana, María Eugenia y Bernabeu-Mestre, Josep, «El problema sanitario de España: saneamiento y medio rural en los primeros decenios del siglo $\mathrm{XX}$, 
Asclepio. Revista de Historia de la Medicina y de la Ciencia, LVIII, 2, Madrid, 2006, 139-164.

Gallart i Fernández, Josep; Rey Lanaspa, Javier y Rovira Marsal, Joan, «Nuevos datos para el conocimiento de la Edad del Bronce en la Litera (Huesca)», Bolskan, 8, Huesca, 1991, 215-242.

Garrido Palacios, José, Zonas húmedas del Somontano de Barbastro (Huesca), Zaragoza, Geodesma, S. L., 2009.

González Hidalgo, José Carlos; Bellot Abad, Juan y Sierralta Jara, Leonel, «Ensayo de evaluación e interpretación de un polígono de regadíos. La Violada, Huesca (España), 1945-1985», Geographicalia, 26, Zaragoza, 1989, 141-154.

González Quijano, Pedro Miguel, «Colonización y repoblación interior», Revista de Obras Públicas, 2.054, Madrid, 4 de febrero de 1915, 49-59.

González Quijano, Pedro Miguel, «Colonización interior y política hidráulica», Revista de Obras Públicas, 2.180, Madrid, 5 de julio de 1917, 317-323.

Hauser y Kobler, Philip, La geografía médica de la Península Ibérica, Madrid, Imprenta de Eduardo Arias, 1913.

Hervás i Puyal, Carlos, Sanitat a Catalunya durant la República i la Guerra Civil. Política i Organització sanitàries: l'impacte del conflicte bèlic, tesis doctoral dirigida por el dr. Josep Termes i Ardèvol, Universitat Pompeu i Fabra, Barcelona, 2004.

Hogan, J. Michael, The Panama Canal in American Politics: Domestic Advocacy and the Evolution of Policy, Carbondale, Illinois, Southern Illinois University Press, 1986.

Hué Herrero, Fernando y Llamas Madurga, Manuel Ramón, «El problema de los canales en los terrenos yesíferos. Medio siglo de experiencia en el Canal de Aragón y Cataluña», Revista de Obras Públicas, 108-109 (t. I), Madrid, $1960-1961,2.948$ y $2.951,910-928$ y $137-151$.

Hunter, J. M. et al., Enfermedades parasitarias y desarrollo hidráulico. Necesidad de una negociación intersectorial, Ginebra, OMS, 1994.

Ibáñez, María Jesús, «El endorreísmo del sector central de la depresión del Ebro», Cuadernos de investigación: Geografía e Historia, I, 1, Logroño, 1975, 35-48.

Ibáñez, María Jesús; Pellicer, Francisco y Echeverría, María Teresa, «Notas geomorfológicas sobre la laguna de Sariñena», Geographicalia, 21-24, Zaragoza, 1984, 25-41.

Ibarra Benlloch, Paloma y de la Riva Fernández, Juan Ramón, «Aportación al análisis de las repercusiones ambientales de la gestión de la Confederación Hidrográfica del Ebro», Geographicalia, 44, Zaragoza, 2003, 75-101.

Jaén Suárez, Omar, «El Canal de Panamá: los efectos sobre el medio ambiente de su construcción y operación hasta el presente», en Medio ambiente y desarrollo en Panamá, Panamá, Universidad de Panamá-Instituto de Estudios Nacionales, Cuadernos Nacionales, 4, 1990. 
Jaén Suárez, Omar, Hombres y ecología en Panamá, Panamá, Editorial Universitaria-Smithsonian Tropical Research Institute, 1981.

Lasanta, Teodoro et al., «Effects of Irrigation on Water Salinization in Semid-arid Environments. A Case Study in las Bardenas, Spain», Cuadernos de Investigación Geográfica, 28, Logroño, 2002, 7-13.

L'arquitectura de l'aigua, Lleida, Pagès editors, 2004.

Le Prince, J. A. y Orenstein, A. J., Mosquito Control in Panama. The Eradication of Malaria and Yellow Fever in Cuba and Panama, New York y London, G. P. Putnam's Sons, 1916.

Lemeunier, Guy, «Drenaje y crecimiento agrícola en la España mediterránea (1500-1800)», Áreas. Revista Internacional de Ciencias Sociales, 17, Murcia, 1997, 31-41.

López, P. L. et al., «Características hidroquímicas generales de las lagunas salinas de la comarca de Los Monegros», Boletín de la Sociedad Entomológica Aragonesa, 24, Zaragoza, 1999, 65-66.

López Cerezo, José A., «El Canal de Panamá III: la tecnología al servicio de la salud», Divulgación y Cultura Científica Iberoamericana, Organización de Estados Iberoamericanos para la Educación, la Ciencia y la Cultura (OEI), s. f. [2013], disponible en http://www.oei.es/historico/divulgacioncientifica/ reportajes016.htm [consultado: 03/11/2017].

Lorenzo Pardo, Manuel, «El Servicio Sanitario de la Confederación», Confederación Sindical Hidrográfica del Ebro, 10, Zaragoza, abril, 1928, 1-3.

Los Monegros, Zaragoza, Gobierno de Aragón-Sodemasa-Prames, 2006.

Marías Cadenas, Sescún, «Por España y por el campo». La Sección Femenina en el medio rural oscense (1939-1977), Huesca, Instituto de Estudios Altoaragoneses, 2011.

Martínez de Pisón, Eduardo, «Consecuencias ecológicas de las obras hidráulicas y de la transformación en regadío», Agricultura y Sociedad, 32, Madrid, julio-septiembre, 1984, 259-272.

Martínez Navarro, Ferrán y Bernabeu Mestre, Josep, «Agricultura y paludismo: a propósito de un debate histórico», en Nájera Morrondo, José Antonio y González Bueno, Antonio (coords.), Malaria: exposición celebrada en la Biblioteca Nacional del 17 de marzo al 7 de junio de 2009, Madrid, Biblioteca Nacional, 2009, 37-50.

Mateu Giral, Josep Joan, La vida económica a les terres de Lleida (1850-2005), Lleida, Pagès editors, 2005.

Mateu González, Josep Joan, El Canal de Aragón y Cataluña: gestación, construcción y puesta en explotación (1782-1940), tesis doctoral dirigida por el dr. Víctor Bretón Solo de Zaldívar, Universitat de Lleida, Lleida, 2015. Disponible en http://hdl.handle.net/10803/380552 [consultado: 03/11/2017].

Maya, José Luis, «El Pantano de Santa Ana (Huesca) y sus materiales en la Edad del Bronce», Bolskan, 8, Huesca, 1991, 199-213. 
Maya, José Luis, y Prada, Alfons, «Aportaciones al poblamiento de las cuencas de los ríos Segre y Cinca durante el inicio de la Edad del Bronce», Bolskan, 6, Huesca, 1989, 85-120.

McCullough, David, Un camino entre dos mares. La creación del Canal de Panamá (1870-1914), Barcelona, Espasa, 2012.

Mesa Venegas, Ana María, «Historical perspective of antimalarial of natural origin», Anales de la Real Academia Nacional de Farmacia, 83, 2, Madrid, 2017, 167-174.

Molina Herranz, Pedro José y Olivera Elfau, Pilar, La laguna de Sariñena, lugar de encuentro, Zaragoza, Instituto de Estudios Altoaragoneses, 1987.

Obiol Menero, Emilio M., «Desecaciones, arroz y demografía en el s. XIX. El caso de "Els Estanys" de Almenara», Cuadernos de Geografía, 55, Valencia, 1994, 109-121.

Ordóñez, B. R., «Enfermedades de alto riesgo asociadas con grandes presas», en Schorr, Thomas S. (ed.), Las represas y sus efectos sobre la salud, México, Organización Panamericana de la Salud, 1984.

Parks, L. F. y Nuermberger, G. A., «The Sanitation of Guayaquil», The Hispanic American Historical Review, 23, 2, Durham, 1943, 197-221.

Pastor, F., «Estado actual del problema palúdico en la zona del Canal de Aragón y Cataluña», Confederación Sindical Hidrográfica del Ebro, 48, Zaragoza, 1931, 13-17.

Pedrocchi Renault, César, «El agua en Los Monegros», en Pedrocchi Renault, C. (coord.), Ecología de Los Monegros. La paciencia como estrategia de supervivencia, Huesca, Instituto de Estudios Altoaragoneses-Centro de Desarrollo de Monegros, 1988.

Pedrocchi Renault, César et al., Estudio multidisciplinar de la laguna, Sariñena (Huesca), Zaragoza, Instituto de Estudios Altoaragoneses, 1986.

Pedrocchi Renault, César y Sanz Sanz, María Ángeles, «El sistema endorreico de Monegros: un ecosistema en vías de extinción», Lucas Mallada. Revista de Ciencias, 3, Huesca, 1991, 93-106.

Pérez Moreda, Vicente, «Notas para una historia del paludismo en España», Jano. Medicina y Humanidades, 728, Barcelona, 1986, 50-64.

Pineo, R. F., «Misery and Death in the Pearl of the Pacific: Health Care in Guayaquil, Ecuador, 1870-1925», The Hispanic American Historical Review, 70, 4, Durham, 1990, 609-637.

Pittaluga, Gustavo, «Los problemas sanitarios de la vida rural», Confederación Sindical Hidrográfica del Ebro, 10, Zaragoza, abril, 1928, 2.

Pittaluga, Gustavo, «El problema del paludismo en las grandes obras hidráulicas», Contribución a la Conferencia Mundial de la Energía, Zaragoza, Industrias Gráficas Uriarte, 1929, 313-327.

Protocolos de la Red Nacional de Vigilancia Epidemiológica. Protocolo de vigilancia de Paludismo, Madrid, Instituto de Salud Carlos III, 2015. 
Ramon-Muñoz, Josep Maria, L'agricultura de regadiu a la Catalunya contemporània: els Canals d'Urgell, 1860-1960, Memoria de Doctorado, Universitat Pompeu i Fabra, Barcelona, 2004.

Ramon-Muñoz, Josep Maria, «Cambio agrario, uso del suelo y regadío: el impacto del Canal de Urgell, 1860-1935», Historia Agraria. Revista de agricultura e historia rural, 59, Murcia, 2013, 43-94.

Rebollo Mesas, Pilar, El Servicio Social de la mujer en la provincia de Huesca (1937-1978), Zaragoza, Gobierno de Aragón-Instituto de Estudios Altoaragoneses, 2003.

Rodriguero, Marcela Silvina, «Wolbachia, una pandemia con posibilidades», $R e$ vista de la Sociedad Entomológica Argentina, 72, 3-4, Buenos Aires, 2013, 117-137.

Rodríguez Ocaña, Esteban; Ballester, Rosa; Perdiguero, Enrique; Medina-Domenech, Rosa y Molero, Jorge, «La lucha contra el paludismo en España en el contexto internacional», Enfermedades Emergentes, 5, 1, Barcelona, 2003a, 41-52.

Rodríguez Ocaña, Esteban; Ballester, Rosa; Perdiguero, Enrique; Medina-Domenech, Rosa y Molero, Jorge, La acción médico-social contra el paludismo en la España metropolitana y colonial del siglo XX, Madrid, CSIC, 2003b.

Rodríguez Ocaña, Esteban y Perdiguero, Enrique, «Las campañas antipalúdicas en España», en Nájera Morrondo, José Antonio y González Bueno, Antonio (coords.), Malaria: exposición celebrada en la Biblioteca Nacional del 17 de marzo al 7 de junio de 2009, Madrid, Biblioteca Nacional, 2009, 97-110.

Ross, Ronald, Mosquito brigades and how to organize them, Londres, George Philip and son, 1902.

Sabaté i Casellas, Ferran, Política sanitaria i social de la Mancomunitat de Catalunya (1914-1924), tesis doctoral dirigida por el dr. Jacint Corbella i Corbella, Universidad de Barcelona, Barcelona, 1992.

Sanicas, Melvin, «Tres modos de matar mosquitos asesinos», El País, Madrid, 5 de octubre de 2017, disponible en https://elpais.com/elpais/2017/10/02/planeta _futuro/1506942181_335723.html [consultado: 11/2017].

Solé i Sabaté, Josep Maria, L'Estany d'Ivars $i$ Vila-sana. La recuperació: d'un somni a una realitat, Lleida, Pagès editors-Consorci Estany d'Ivars-Vilasana, 2007.

Stepan, Nancy, «The Interplay between Socio-Economic Factors and Medical Science: Yellow Fever Research, Cuba and the United States», Social Studies of Science, 8, 4, Londres, 1978, 397-423.

Sutter, Paul, "AArrancarle los dientes al trópico": ambiente, enfermedad y el programa sanitario de Estados Unidos en Panamá, 1904-1914», Papeles de Población, 24, México, abril-junio, 2000, 61-93. 
Sutter, Paul, «El control de los zancudos en Panamá: los entomólogos y el cambio ambiental durante la construcción del canal», Historia Crítica, 30, Bogotá, julio-diciembre, 2005, 67-90.

Utrera Caro, Sebastián Félix, La incidencia ambiental de las obras hidráulicas: régimen jurídico, Madrid, Editorial Dykison, 2002.

Valero Garcés, Blas L., «Las saladas de Los Monegros: registros únicos de cambios ambientales y climáticos del pasado», Boletín de la Sociedad Entomológica Aragonesa, 24, Zaragoza, 1999, 63-64.

Vicedo Rius, Enric, «Models de poblament i colonització agrària en l'etapa final de l'antic regime a Catalunya. Les terres de Lleida: recuperació, poblament i expansió», en Bolòs, Jordi y Vicedo, Enric (eds.), Poblament, territori i Història Rural, Lleida, Institut d'Estudis Ilerdencs-Diputació de Lleida, 2009, 119-137.

Vila i Ricart, Jaume, Els Canals d'Urgell i la seva història, Lleida, Diputació de Lleida, 1992.

Worboys, Michael y Manson, Ross, «Colonial Medical Policy: Tropical Medicine in London and Liverpool, 1899-1914», en McLeod, Roy y Milton, Lewis (eds.), Disease, Medicine and Empire: Perspectives on Western Medicine and the Experience of European Expansion, Londres y Nueva York, Rutledge, 1988.

Xi, Z.; Khoo, C. C. y Dobson, S. L., «Wolbachia Establishment and Invasion in an Aedes aegypti Laboratory Population», Science, 310, 5746, Washington D. C., 2005, 326-328. 